Article

\title{
Assessment of the Effect of Wind Load on the Load Capacity of a Single-Layer Bar Dome
}

\author{
Dominika Opatowicz, Urszula Radoń and Paweł Zabojszcza * \\ Faculty of Civil Engineering and Architecture, Kielce University of Technology, 25-314 Kielce, Poland; \\ dominika.opatowicz@gmail.com (D.O.); zmbur@tu.kielce.pl (U.R.) \\ * Correspondence: pawelzab@tu.kielce.pl
}

Received: 26 August 2020; Accepted: 7 October 2020; Published: 13 October 2020

\begin{abstract}
The main purpose of the paper was the assessment of the effect of wind load on the load capacity of a single-layer bar dome. Additionally, which numerical method is appropriate for low-rise single-layer bar domes was checked. In order to explain the effect of the height-to-span ratio on the selection of the appropriate calculation model and method of analysis of the bar dome, an example of the known von Mises truss was proposed. Two cases of von Mises truss differing in the height-to-span ratio were considered. For the shallow structure, a significant change in the value of the stiffness matrix determinant and the current stiffness parameter was observed. A similar tendency in the behavior of the structure can be observed on fragments of larger structures, including shallow single-layer steel domes. These problems are described on the basis of the dome, which is located on top of the building housing the restaurant. This structure is subjected to large displacement gradients and the actual configuration is taken into account in analysis. The analysis showed that there is a change in stiffness for these structures, and, therefore, that such structures should be designed according to geometric nonlinear analysis (GNA).
\end{abstract}

Keywords: single-layer bar dome; linear bifurcation analysis; geometric nonlinear analysis

\section{Introduction}

For proper assessment of structural safety, it is necessary to select the appropriate computational model and methods of structural analysis. It is essential for the methods to most accurately represent the behavior of the structure. This concerns both the adoption of a static diagram, loading, and also a model of the behavior of the structure, bars, supports, and nodes under load.

The structural analysis means and scope are also highly affected by the behavior of the element cross-section in compression and bending. The process of structural design was streamlined due to the introduction of the cross-section classification. The class of the cross-section depends on the shape, slenderness of the element walls (width-to-thickness ratio $c / t$ ), the member yield strength, and the distribution of compressive stress. When compressive stress does not occur, it is unnecessary to specify the class of cross-section [1]. The cross-section class indicates the degree of the element resistance to the local stability failure in the elastic or plastic state. Consequently, it is of key importance for the selection of the computational model and the criterion of the cross-section capacity [2,3].

Global instability of the steel bars is equivalent to their failure. Global instability of compression element, called buckling, can have one of three modes: flexural (the bar is bent in the plane having the lowest stiffness), torsional (the bar twists around the longitudinal axis), and flexural-torsional (the bar bending is at the same time accompanied by its torsion). Global instability of the element in bending, called lateral torsional buckling, occurs when the bending moment reaches the critical value. Beam lateral torsional buckling is initiated by the compression flange buckling out of the bending plane, and that is immediately transformed into beam torsion. The possibility of stability failure depends on 
the bar slenderness. The bar of sufficiently low slenderness is stable. With an increase in slenderness, at the same cross-sectional area, the bar becomes more susceptible to global instability. Class 4 steel bars are particularly vulnerable to global stability failure [4,5].

Problems related to the selection of the appropriate calculation model and method of the stability analysis of the structures were the topic of many papers. In 1997, Oda and Usami presented a paper on the method of designing steel frame stability based on a second order elastic analysis, in which a new formula of equivalent initial deflection was proposed and a methodology using the buckling mode curvature was introduced to allow systematic application of this formula to irregular frames of any shape [6]. Fan, Yan, and Cao, in their article [7], presented a multibeam method for simulating the initial curvature of rods, and two methods of numerical modelling were adopted to introduce the initial curvature of rods for reticulated shell structures using ANSYS software. In [8], the authors present a fully analytical model to determine the deformations in the jointing components under the structure loading and investigate its influence on their post-buckling behavior. In [9], a snap-through of two shallow single-layer reticulated domes under unilateral displacement control is analyzed. An interesting experimental study and finite-element (FE) analysis of a single-layer Kiewitt Lamella dome and a geodesic dome was carried out to understand the mechanism of internal force redistribution in the progressive collapse of domes, by $\mathrm{Xu}, \mathrm{Han}$, Parke, and Liu and is presented in [10], while, in [11], the authors present a method to identify the most critical members in a single-layer latticed dome on the basis of the progressive collapse mechanism. The critical member identification method is proposed, using an index that implicitly estimates the relative vulnerability to node buckling following the removal of a member to determine the criticality of this member, and based on the established understanding of the progressive collapse mechanism and the factors influencing the node buckling resistance, several methods for increasing the progressive collapse resistance of single-layer latticed domes are suggested. A paper on the impact of material nonlinearities on global analysis and stability of steel frame structures worth recommending is [12].

The main purpose of the paper was the assessment of the effect of wind load on the load capacity of a single-layer bar dome. Additionally, which computed method is appropriate for low-rise single-layer bar domes was checked. In order to explain the effect of the height-to-span ratio on the selection of the appropriate calculation model and method of analysis of the bar dome, an example of the known von Mises truss was proposed. Two cases of von Mises truss differing in the height-to-span ratio were considered. For a shallow structure, a significant change in the value of the stiffness matrix determinant and the current stiffness parameter was observed. A similar tendency in the behavior of the structure can be observed on fragments of larger structures, including shallow single-layer steel domes. These problems are described on the basis of the dome, which is located on top of the building housing the restaurant. This structure is subjected to large displacement gradients, and the actual configuration is taken into account in analysis. The analysis showed that there is a change in stiffness for these structures, hence the conclusion that such structures should be designed according to GN analysis.

\section{Materials and Methods}

Modern theory of structural stability started with Koiter's doctoral thesis [13]. The study marked the beginning of theoretical investigations into post-buckling behavior of structures near critical states. The sensitivity of structures to initial imperfections was analyzed. The development of incremental models and iterative procedures started the nonlinear structural analysis (Oden [14], Bathe [15], Belytschko [16], Kleiber [17]).

The choice of computational method depends on the type of system. The simplest-linear analysis-does not take into account changes in the rigidity of the structure and the effect of this change on its behavior. The linear analysis is based on linear geometric relations between displacements and strains. In addition, the relations between stresses and strains, and also equations describing the load-displacement relation are linear in character. Geometric nonlinearity and stability issues related to 
that are disregarded. The linear analysis does not account for the occurrence of overall stability failure of bars or the whole system, or the local stability failure of the elements of bar cross-sections $[18,19]$. This is equivalent to the assumption that the structure has ideal (not showing up any imperfections) initial geometry that does not change (the strain induced by load is not considered). The method takes into account elastic strain. In this method, displacements are proportional to the loads applied. The principle of superposition is followed in the assessment of internal forces in the structure and strength utilization in the cross-sections. In this model, the elastic capacity of the structure is restricted by the elasticity limit of the material (in practice, the yield point). The linear analysis in terms of the finite element method FEM boils down to the solution of a linear system of algebraic Equation (1):

$$
\mathbf{K}_{\mathbf{L}} \cdot \mathbf{q}=\mathbf{P}
$$

where: $\mathbf{K}_{\mathrm{L}}$-linear stiffness matrix of the structure; $\mathbf{q}-$ vector of nodal displacements; $\mathbf{P}-$ vector of nodal load.

The FEM software is additionally equipped with linear bifurcation analysis (LBA). The goal of LBA is to solve the eigenvalue problem:

$$
\left[\mathbf{K}_{\mathbf{L}}+\mu \cdot \mathbf{K}_{\mathbf{G}}\right] \cdot \mathbf{q}=\mathbf{0}
$$

where: $\mathbf{K}_{\mathbf{G}}$-geometrical stiffness matrix.

The geometric stiffness matrix $\mathbf{K}_{\mathbf{G}}$ is identified as the initial stress stiffness matrix. Eigenvalues $\mu$ are critical load multipliers. Eigenvector $\mathbf{q}$ illustrates the form of structure deformation. Running the analysis allows the user to quickly verify how close to instability the analyzed load condition is. However, analysis is still conducted in the field of linear physical and geometrical relationships.

Only the geometrically nonlinear analysis (GNA) is capable of a full description of the possible forms of instability. This type of analysis can provide the equilibrium path and information about the post-critical behavior of the structure. For nonlinear discrete systems which are formulated on the basis of FEM, the mathematical model corresponds to a set of nonlinear algebraic equations. The set can be formulated in a total or in an incremental form. In the first case, equations have the form:

$$
\mathbf{K}_{\mathrm{s}}(\mathbf{q}) \mathbf{q}=\mathbf{P}
$$

where: $\mathbf{K}_{\mathbf{s}}$-secant stiffness matrix of the structure.

In the second case, equations have the form:

$$
\mathbf{K}_{\mathrm{T}}(\mathbf{q}) \cdot \Delta \mathbf{q}=\Delta \mu \cdot \mathbf{P}+\mathbf{R}
$$

where: $\mathbf{K}_{\mathbf{T}}(\mathbf{q})$-tangent stiffness matrix of the structure; $\mathbf{R}=\mathbf{P}-\mathbf{F}$-vector of residual forces; $\mathbf{F}-$ vector of internal forces.

In the equilibrium state $\mathbf{R}=\mathbf{0}$, while in the iterative process, the norm of $\mathbf{R}$ defines the distance from the equilibrium state. The iterative process converges if $\mathbf{R} \rightarrow \mathbf{0}$.

The tangent stiffness matrix $\mathbf{K}_{\mathrm{T}}$ of the structure arises as a result of the assembly of the stiffness matrices of the elements: $\mathbf{K}_{\mathbf{T}}^{\mathrm{e}}$

$$
\mathbf{K}_{\mathrm{T}}=\sum_{\mathrm{i}=1}^{\mathrm{e}} \mathbf{K}_{\mathrm{T}}^{\mathrm{e}}=\sum_{\mathrm{i}=1}^{\mathrm{e}}\left(\mathbf{K}_{\mathrm{L}}^{\mathrm{e}}+\mathbf{K}_{\mathrm{G}}^{\mathrm{e}}+\mathbf{K}_{\mathrm{u} 1}^{\mathrm{e}}+\mathbf{K}_{\mathrm{u} 2}^{\mathrm{e}}\right)
$$

where: $\mathbf{K}_{\mathrm{T}}^{\mathrm{e}}$ is the tangent stiffness matrix of the element composed of linear stiffness matrix $\mathbf{K}_{\mathbf{L}^{\prime}}^{\mathrm{e}}$ geometric stiffness matrix $\mathbf{K}_{\mathbf{G}^{\prime}}^{\mathbf{e}}$, and nonlinear stiffness matrices: $\mathbf{K}_{\mathbf{u} 1}^{\mathbf{e}}$ and $\mathbf{K}_{\mathbf{u} 2}^{\mathbf{e}}$.

In GNA, it is extremely important to determine changes in structure stiffness in the load process. An often used measure of structural rigidity is the matrix determinant det $\left(\mathbf{K}_{\mathrm{T}}\right)$. A more effective proposition to describe these changes was proposed by Bergan and Soreide in [20]. They characterize the behavior of a multidimensional nonlinear system by using one scalar quantity, the current stiffness 
parameter (CSP), representing the ratio of two quadratic forms formulated for the tangent stiffness matrix at the initial $\mathrm{K}_{\mathrm{T}}^{0}$ and current times $\mathbf{K}_{\mathrm{T}}^{\mathrm{i}}$ :

$$
\operatorname{CSP}=\frac{\Delta \mathbf{q}^{0 \mathrm{~T}} \cdot \mathbf{K}_{\mathbf{T}}^{0} \cdot \Delta \mathbf{q}^{0}}{\Delta \mathbf{q}^{\mathrm{iT}} \cdot \mathbf{K}_{\mathrm{T}}^{\mathrm{i}} \cdot \Delta \mathbf{q}^{\mathrm{i}}}
$$

This parameter can be used as a measure for the change in the tangent stiffness matrix $\mathbf{K}_{\mathrm{T}}$ during the motion in the $\mathrm{N}$-dimensional, displacement solution space. Figure 1a shows a typical snap-through problem (load parameters versus some norm of displacement vector $\|\mathbf{q}\|$ ). The associated curve for CSP as a function of $\|\mathbf{q}\|$ is traced in Figure $1 b$. It is noticeable that at the extreme points of the load-displacement curve, CSP has the value zero. In this situation, the incremental stiffness matrix $\mathrm{K}_{\mathrm{T}}$ is singular. CSP is positive for the stable branches of the load-displacement curve. The instable configurations are characterized by negative values of CSP.

\section{a)}

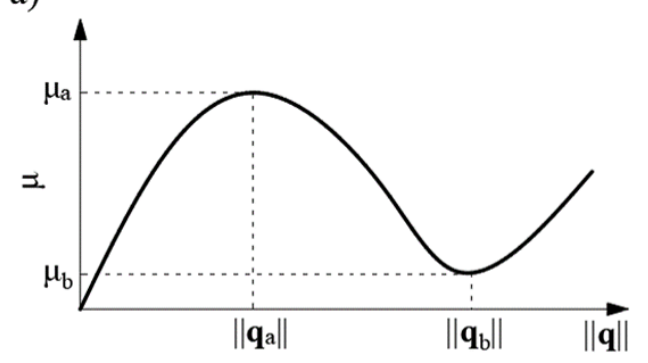

b)

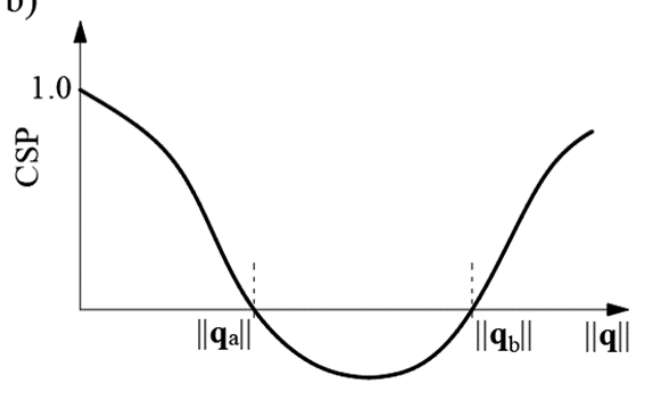

Figure 1. (a) Dependence of load parameter $\mu$ on the norm of $\|\mathbf{q}\| ;(\mathbf{b})$ dependence of the current stiffness parameter (CSP) on the norm of $\|\mathbf{q}\|$.

Analysis of stability of bar structures with the finite element method (FEM) involves solving large systems of nonlinear equations. The relation between displacements and loads in a $(\mathrm{N}+1)$-dimensional space is described by the load-displacement path. Elastic stability is closely related to singularities along this path. These singular points are considered to be critical ones. They include a limit point known as snapping and a bifurcation point known as buckling. The set of equations can be completed by a constraint equation to formulate an extended set of equations. An advantage of such a formulation is equivalent treatment of displacements $q(\eta)$ and load parameter $\mu(\eta)$ where $\eta$ is the so-called control parameter. The two most simple ways to control the incremental process are: $\mu=\eta$ and $q_{i}=\eta$ with the load parameter $\mu$ and chosen displacement $\mathrm{q}_{\mathrm{i}}$ being the controlling parameters. With the first of the two methods, subsequent points are the points of intersection between $\mu=\eta_{\mathrm{i}}$ and the equilibrium path, and with the second method-as the points of intersection between $q_{k}=\eta_{i}$ with the same solution curve (Figure 2). Both procedures are inefficient at the vicinity of local extremum of the controlling parameter. 

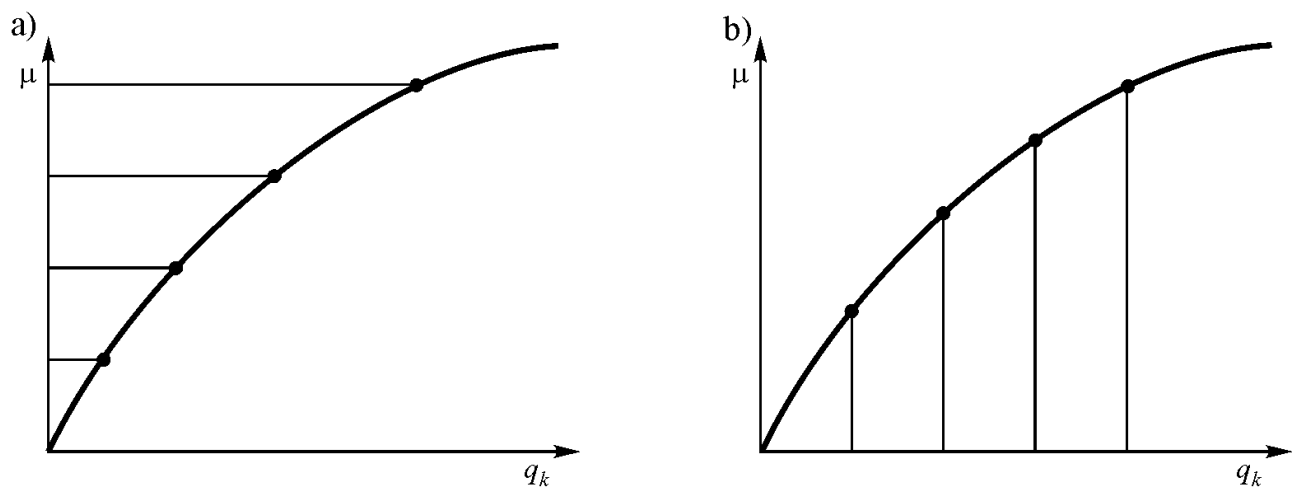

Figure 2. Control of an incremental process: (a) by load, (b) by displacement.

Riks [21,22] notes that at the limit points, the equilibrium path is tangent to the corresponding hyperplane: the angle $\theta$ between the tangent to the equilibrium path and the normal to the hyperplane is $\pi / 2$. The intersection of the equilibrium path with this hyperplane is thus well defined when the angle $\theta$ is equal to or close to zero and poorly defined if it is close or equal to $\pi / 2$. In this sense, the perfect family of surfaces will intersect the equilibrium path in perpendicular direction so that for every $\eta$ the angle $\theta$ is zero (Figure 3).
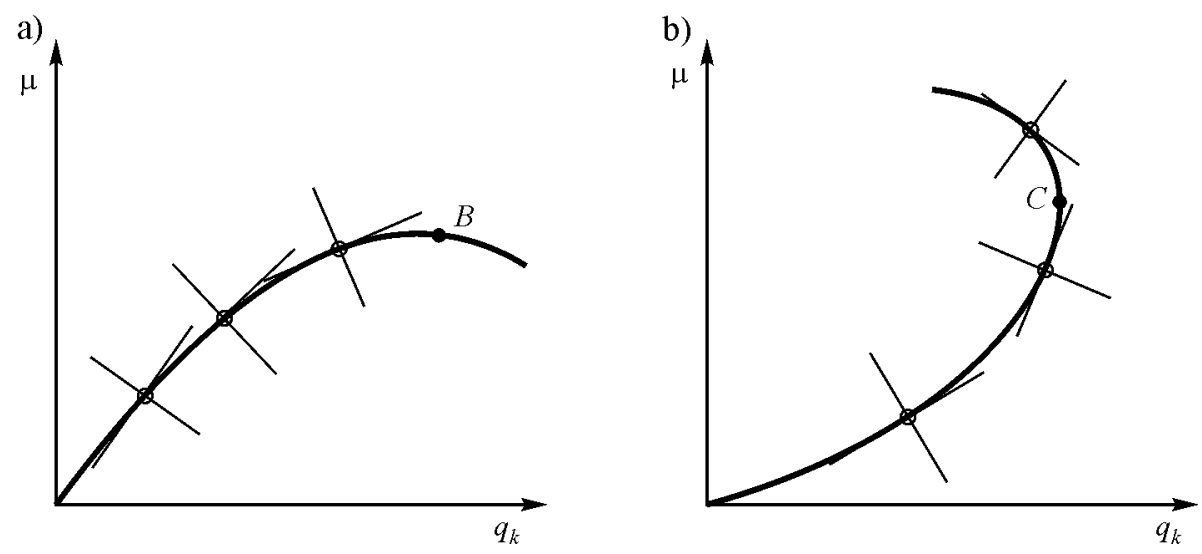

Figure 3. Tracing an equilibrium path with (a) limit point, (b) turning point.

An equation describing a "perfect" family of surfaces cannot be constructed because it is based on the equilibrium path which is unknown. However, an approximation can be used so that the angle $\theta$ is close to zero. Riks $[21,22]$ proposed the following constraint equation:

$$
\left(\mathbf{q}_{\alpha}\right)^{\mathbf{T}} \cdot\left(\mathbf{q}-\mathbf{q}_{\alpha}\right)+\mu_{\alpha} \cdot\left(\mu-\mu_{\alpha}\right)=\left(\eta-\eta_{\alpha}\right)
$$

where: $\mathbf{q}$-generalized coordinate vector; $\eta-\eta_{\alpha}$-parameter approximating the arc length; the dots appearing above the symbols indicate derivatives with respect to the arc length.

Equation (7) defines a hyperplane that is perpendicular to the vector $\left(\mathbf{q}_{\alpha}, \mu_{\alpha}\right)$ and distant from the point $\left(\mathbf{q}_{\alpha}, \mu_{\alpha}\right)$ by $\left(\eta-\eta_{\alpha}\right)$. It will intersect the equilibrium path almost perpendicular when the distance $\eta-\eta_{\alpha}$ is sufficiently small.

In this paper, the incremental-iterative method of the constant arc-length developed by Riks was applied to solve nonlinear equations. To compute the critical points, it is necessary to update the global tangent stiffness matrix at every iteration step. Four years after the arc-length method was proposed by Riks, Crisfield [23] came up with an alternative to that method. The latter was employed 
in many commercial FEM programs. Another variant of the constant arc-length method, similar to that developed by Crisfield, was put forward by Ramm [24].

In the review of arc-length methods, it is worth mentioning the pioneering work by Wempner [25]. The incremental procedures for tracing the equilibrium paths are still being developed in the works of Ritto-Correa et al. [26], Leon et al. [27], and Rezaiee et al. [28] etc.

Problems of the stability analysis with FEM is currently the subject of many papers [29-33].

The theory of stability deals with critical load and deformation of structures which are associated with sudden, quantitative changes of the structure state. The actual configurations have to be taken into account in the theory of stability of structure. This means that stability equations are actually nonlinear. They can be linearized in the case of linear bucking analysis.

In the paper, the dome is subjected to large displacement gradients and susceptible to stability loss from the condition of node snapping. Nonlinear geometrical relations are defined in the Lagrangian description. The constitutive relations are linear. The geometrical nonlinear analysis is performed using the "Autodesk Robot Structural Analysis" software (FEM code) (Autodesk Revit 2020, San Rafael, CA, USA).

\subsection{Truss Element Description}

In order to explain the effect of the height-to-span ratio on the selection of the appropriate calculation model and method of analysis of the bar dome, an example of the known von Mises truss was proposed. These issues are discussed in the pioneering work of Pecknold et al. [34].Additionally, notice that the former analytical solution has been extended to unsymmetric von Mises trusses by Ligarò and Valvo [35], to three-dimensional pyramidal trusses by Ligarò and Valvo [36], and to more general planar and space trusses by Rezaiee-Pajand et al. [37].

The truss is analyzed in the undeformed (initial) configuration ${ }^{0} \mathrm{C}$ and in the deformed configuration ${ }^{\mathrm{t}} C$ and ${ }^{\mathrm{t}+\Delta \mathrm{t}} C$ (Figure 4). The following material and geometric constants were adopted: $E$-Young's modulus; $l_{0}$-the initial length; $A_{0}$-the initial cross-sectional area; $l$-the length in the deformed configuration; $A$-the cross-sectional area in the deformed configuration. The deformation field in the deformed configuration ${ }^{\mathrm{t}} C$ is described by four components, $\mathrm{q}=\left\{\mathrm{u}_{1}, \mathrm{v}_{1}, \mathrm{u}_{2}, \mathrm{v}_{2}\right\}$, and the displacement increment between time $t$ and $t+\Delta t$ is described by vector $\Delta \mathbf{q}=\left\{\Delta \mathrm{u}_{1}, \Delta \mathrm{v}_{1}, \Delta \mathrm{u}_{2}, \Delta \mathrm{v}_{2}\right\}$. These displacement vectors correspond to nodal force vectors: $Q=\left\{U_{1}, V_{1}, U_{2}, V_{2}\right\}$, and $\Delta Q=\left\{\Delta U_{1}\right.$, $\left.\Delta \mathrm{V}_{1}, \Delta \mathrm{U}_{2}, \Delta \mathrm{V}_{2}\right\}$.

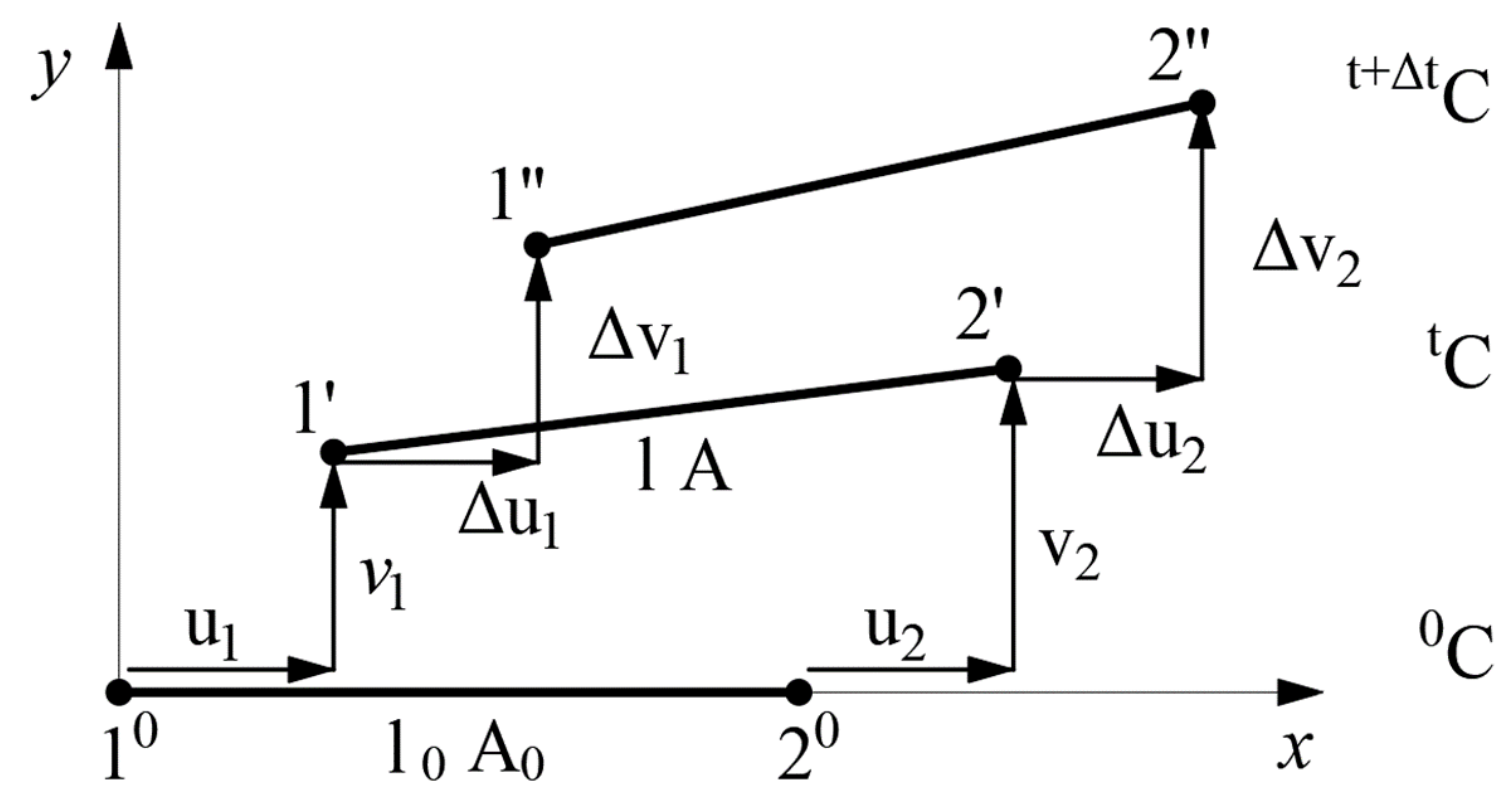

Figure 4. Truss element in the undeformed (initial), ${ }^{0} C$, and deformed ${ }^{t} C$ and ${ }^{t+\Delta t} C$ configurations. 
The displacement field $\mathbf{u}=[\mathbf{u ~ v}]^{\mathrm{T}}$ is interpolated by linear shape functions:

$$
\begin{gathered}
\mathbf{u}=\mathbf{N} \cdot \mathbf{q}, \\
\text { where }: \mathbf{N}=\left[\begin{array}{cccc}
1-\xi & 0 & \xi & 0 \\
0 & 1-\xi & 0 & \xi
\end{array}\right], \xi=\frac{\mathbf{x}}{l}
\end{gathered}
$$

The strain tensor in this case reduces to one nonzero quantity of the Green-Lagrange tensor that characterizes the elongation of a bar:

$$
\varepsilon={ }^{\mathrm{t}} \varepsilon=\mathrm{u}^{\prime}+\frac{1}{2}\left(\mathbf{u}^{\prime 2}+\mathbf{v}^{\prime 2}\right)=\mathbf{L} \cdot \mathbf{N} \cdot{ }^{\mathrm{t}} \mathbf{q}+\frac{1}{2}\left({ }^{\mathrm{t}} \mathbf{g}\right)^{\mathrm{T}} \cdot{ }^{\mathrm{t}} \mathbf{g}=\mathbf{B}_{0} \cdot{ }^{\mathrm{t}} \mathbf{q}+\frac{1}{2}\left({ }^{\mathrm{t}} \mathbf{g}\right)^{\mathrm{T}} \cdot \mathbf{g}
$$

where: $\mathrm{L}=\frac{1}{1_{0}}\left[\begin{array}{cc}\frac{\mathrm{d}}{\mathrm{d} \xi} & 0\end{array}\right]$-matrix of differential operators; ${ }^{\mathrm{t}} \mathbf{g}=\left[\begin{array}{cc}\mathrm{u}^{\prime} & \mathrm{v}^{\prime}\end{array}\right]^{\mathrm{T}}$-vector of displacement gradients, $\mathbf{B}_{0}=\mathbf{L} \cdot \mathbf{N}$

Equation (9) accounts for the effect of geometric nonlinearity, which means that large displacements were taken into account $[17,29]$. The Green-Lagrange strain tensor is coupled to the Piola-Kirchhoff second stress tensor. We use the initial reference configuration; thus, axial force $S$ defined as $S=E A \varepsilon$ is not the real force in the bar. It corresponds to component $S_{11}=\sigma$ of the 2nd Piola-Kirchhoff symmetric stress tensor. The real axial force $S^{\prime}=S \cdot l / l_{0}$.

Displacement, strain, and stress fields in the deformed configuration ${ }^{t+\Delta t} C$ are as follows:

$$
\begin{aligned}
& { }^{\mathrm{t}+\Delta \mathrm{t}} \mathbf{q}={ }^{\mathrm{t}} \mathbf{q}+\Delta \mathbf{q}, \\
& { }^{\mathrm{t}+\Delta \mathrm{t}} \varepsilon={ }^{\mathrm{t}} \varepsilon+\Delta \varepsilon, \\
& { }^{\mathrm{t}+\Delta \mathrm{t}} \sigma={ }^{\mathrm{t}} \sigma+\Delta \sigma
\end{aligned}
$$

where: ${ }^{\mathrm{t}} \mathbf{q},{ }^{\mathrm{t}} \varepsilon,{ }^{\mathrm{t}} \sigma$-displacements, strain, and stress at time $\mathrm{t} ; \Delta \mathbf{q}, \Delta \varepsilon, \Delta \sigma$-increments between time $\mathrm{t}$ and $t+\Delta t$. Strain increment can be written as:

$$
\Delta \varepsilon=\left[\mathbf{B}_{0}+\mathbf{B}_{1}(\mathbf{g})+\frac{1}{2} \mathbf{B}_{2}(\Delta \mathbf{q})\right] \Delta \mathbf{q}
$$

where: $\mathbf{B}_{1}=\left({ }^{\mathrm{t}} \mathbf{g}\right)^{\mathrm{T}} \cdot \Gamma=\frac{1}{l_{0}}\left[-\mathrm{u}^{\prime}-\mathrm{v}^{\prime} \mathrm{u}^{\prime} \mathrm{v}^{\prime}\right]$,

$\mathbf{B}_{2}=(\Delta \mathbf{q})^{\mathrm{T}} \cdot \Gamma^{\mathrm{T}} \cdot \Gamma=\frac{1}{1_{0}^{2}}\left[-\left(\Delta \mathrm{u}_{2}-\Delta \mathrm{u}_{1}\right)-\left(\Delta \mathrm{v}_{2}-\Delta \mathrm{v}_{1}\right)\left(\Delta \mathrm{u}_{2}-\Delta \mathrm{u}_{1}\right)\left(\Delta \mathrm{v}_{2}-\Delta \mathrm{v}_{1}\right)\right]$,

$\Delta \mathrm{u}=\mathrm{u}_{2}-\mathrm{u}_{1}, \Delta \mathrm{v}=\mathrm{v}_{2}-\mathrm{v}_{1}$

Stress increments depend on the physical model adopted. For a linear-elastic material, Hooke's law-i.e., a linear relationship between stress and strain—is valid:

$$
\Delta \sigma=\mathrm{E} \cdot \Delta \varepsilon
$$

Equilibrium equations of the element have the form:

$$
\left[\mathbf{K}_{\mathrm{L}}+\mathbf{K}_{G}+\mathbf{K}_{\mathrm{u} 1}+\mathbf{K}_{\mathrm{u} 2}\right] \Delta \mathbf{q}={ }^{\mathrm{t}} \mathbf{Q}-\mathbf{F}+\Delta \mathbf{Q}
$$

$\mathrm{F}^{\mathrm{e}}$ is the vector of internal forces in the element:

$$
\mathbf{F}=\mathrm{S}\left\{-1-\frac{\Delta \mathrm{u}}{\mathrm{l}_{0}},-\frac{\Delta \mathrm{v}}{\mathrm{l}_{0}}, 1+\frac{\Delta \mathrm{u}}{\mathrm{l}_{0}}, \frac{\Delta \mathrm{v}}{\mathrm{l}_{0}}\right\}
$$


For a plane truss element, these matrices take the form:

$$
\begin{gathered}
\mathrm{K}_{\mathrm{L}}=\frac{\mathrm{EA}_{0}}{1_{0}}\left[\begin{array}{cccc}
1 & 0 & -1 & 0 \\
0 & 0 & 0 & 0 \\
-1 & 0 & 1 & 0 \\
0 & 0 & 0 & 0
\end{array}\right], \mathrm{K}_{G}=\frac{\mathrm{S}}{1_{0}}\left[\begin{array}{cccc}
1 & 0 & -1 & 0 \\
0 & 1 & 0 & -1 \\
-1 & 0 & 1 & 0 \\
0 & -1 & 0 & 1
\end{array}\right], \\
\mathrm{K}_{\mathrm{u} 1}=\frac{\mathrm{EA}_{0}}{1_{0}^{2}}\left[\begin{array}{cccc}
\Delta \Delta \mathrm{u} & \Delta \mathrm{v} & -2 \Delta \mathrm{u} & -\Delta \mathrm{v} \\
\Delta \mathrm{v} & 0 & -\Delta \mathrm{v} & 0 \\
-2 \Delta \mathrm{u} & -\Delta \mathrm{v} & 2 \Delta \mathrm{u} & \Delta \mathrm{v} \\
-\Delta \mathrm{v} & 0 & \Delta \mathrm{v} & 0
\end{array}\right] \\
\mathrm{K}_{\mathrm{u} 2}=\frac{\mathrm{EA}_{0}}{1_{0}^{3}}\left[\begin{array}{cccc}
\Delta \mathrm{u}^{2} & \Delta \mathrm{u} \Delta \mathrm{v} & -\Delta \mathrm{u}^{2} & -\Delta \mathrm{u} \Delta \mathrm{v} \\
\Delta \mathrm{u} \Delta \mathrm{v} & \Delta \mathrm{v}^{2} & -\Delta \mathrm{u} \Delta \mathrm{v} & -\Delta \mathrm{v}^{2} \\
-\Delta \mathrm{u}^{2} & -\Delta \mathrm{u} \Delta \mathrm{v} & \Delta \mathrm{u}^{2} & \Delta \mathrm{u} \Delta \mathrm{v} \\
-\Delta \mathrm{u} \Delta \mathrm{v} & -\Delta \mathrm{v}^{2} & \Delta \mathrm{u} \Delta \mathrm{v} & \Delta \mathrm{v}^{2}
\end{array}\right]
\end{gathered}
$$

\subsection{Frame Element Description}

In the second example, the Schwedler dome consisting of 224 frame elements and 81 nodes was analyzed. The following is a description of the plane frame element analogous to the description of the truss element presented in chapter 2.2. Extension to space frame elements is possible [29]

The frame element description was analyzed in the undeformed (initial) configuration ${ }^{0} \mathrm{C}$ and in the deformed configurations ${ }^{\mathrm{t}} \mathrm{C}$ and ${ }^{\mathrm{t}+\Delta \mathrm{t}} \mathrm{C}$ (Figure 5). The following material and geometric constants were adopted: $E$-Young's modulus; $l_{0}$ —the initial length; $A_{0}$-the initial cross-sectional area; $I_{0}$-the initial moment of inertia; $l$-the length in the deformed configuration; $A$-the cross-sectional area in the deformed configuration; $I$-moment of inertia in the deformed configuration.

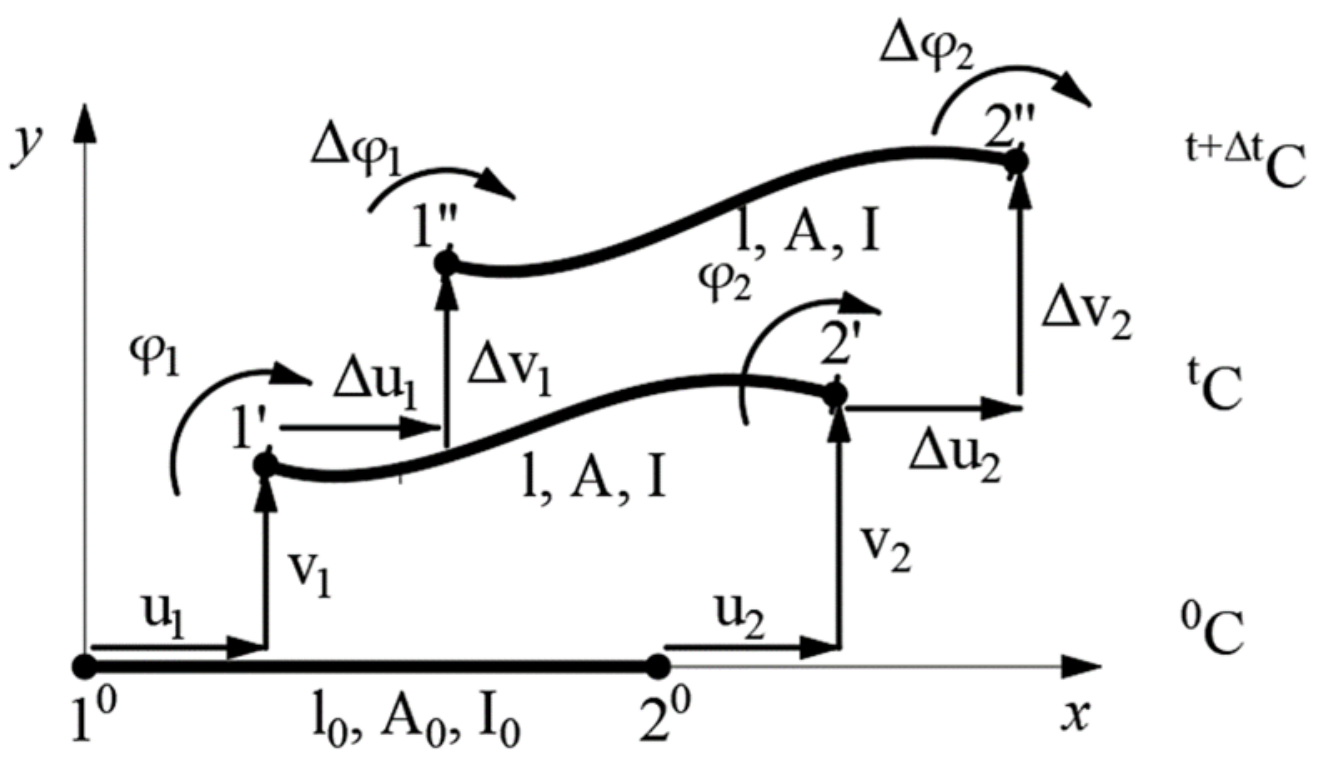

Figure 5. Frame element in the undeformed (initial), ${ }^{0} \mathrm{C}$, and deformed ${ }^{\mathrm{t}} \mathrm{C}$ and ${ }^{\mathrm{t}+\Delta \mathrm{t}} \mathrm{C}$ configurations.

The deformation field in the deformed configuration ${ }^{t} C$ is described by six components, ${ }^{t} \mathbf{q}=\left\{\mathrm{u}_{1}\right.$, $\left.\mathrm{v}_{1}, \varphi_{1}, \mathrm{u}_{2}, \mathrm{v}_{2}, \varphi_{2}\right\}$, and the displacement increment between time $\mathrm{t}$ and $\mathrm{t}+\Delta \mathrm{t}$ is described by vector $\Delta \mathbf{q}=\left\{\Delta \mathrm{u}_{1}, \Delta \mathrm{v}_{1}, \Delta \varphi_{1}, \Delta \mathrm{u}_{2}, \Delta \mathrm{v}_{2}, \Delta \varphi_{2}\right\}$. These displacement vectors correspond to nodal force vectors: ${ }^{\mathrm{t}} \mathbf{Q}=\left\{\mathrm{U}_{1}, \mathrm{~V}_{1}, \Phi_{1}, \mathrm{U}_{2}, \mathrm{~V}_{2}, \Phi_{2}\right\}$, and $\Delta \mathbf{Q}=\left\{\Delta \mathrm{U}_{1}, \Delta \mathrm{V}_{1}, \Delta \Phi_{1}, \Delta \mathrm{U}_{2}, \Delta \mathrm{V}_{2}, \Delta \Phi_{2}\right\}$. 
The displacement field is interpolated using the matrix of the shape function and the nodal displacement vector:

where :

$$
{ }^{\mathrm{t}} \mathbf{u}=\mathbf{N} \cdot \mathbf{q}=[\mathbf{u ~ v}]^{\mathrm{T}},
$$

$$
\mathbf{N}=\left[\begin{array}{cccccc}
1-\xi & 0 & 0 & \xi & 0 & 0 \\
0 & 1-3 \xi^{2}+2 \xi^{3} & 1 \cdot \xi(1-\xi)^{2} & 0 & \xi^{2}(3-2 \xi) & -1 \cdot \xi^{2}(1-\xi)
\end{array}\right], \quad \xi=\frac{\mathbf{x}}{1}
$$

It is visible that the approximation of displacement $\mathrm{u}, \mathrm{v}$ by means of polynomials of the first and third orders, respectively, leads to Hermitian shape functions.

We assume that the Bernoulli-Euler hypothesis about the undeformable, perpendicular cross-section is valid. The strain at the point of cross-section is determined by the linear function of variable y:

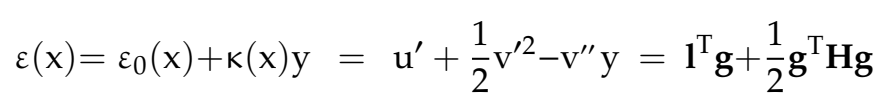

where: $\mathbf{1}=\left\{\begin{array}{lll}1 & 0 & -\mathrm{y}\end{array}\right\}$-matrix of differential operators; ${ }^{\mathrm{t}} \mathbf{g}=\left[\begin{array}{ccc}\mathrm{u}^{\prime} & \mathrm{v}^{\prime} & \mathrm{v}^{\prime \prime}\end{array}\right]^{\mathrm{T}}$-vector of displacement gradients, $\mathbf{H}=\left[\begin{array}{lll}0 & 1 & 0\end{array}\right]$.

The vector of generalized stresses and modular matrix are:

$$
\boldsymbol{\sigma}=\left[\begin{array}{c}
\mathrm{S} \\
\mathrm{M}
\end{array}\right], \quad \mathbf{E}=\left[\begin{array}{c}
\mathrm{EA} \\
\mathrm{EI}
\end{array}\right], \quad \varepsilon=\left[\begin{array}{c}
\varepsilon_{0} \\
\kappa
\end{array}\right]
$$

where: S—axial force; $\mathrm{M}$-bending moment

Stress increments depend on the physical model adopted. For a linear-elastic material, Hooke's law-i.e., a linear relationship between stress and strain-is valid:

$$
\Delta \sigma=\mathrm{E} \cdot \Delta \varepsilon
$$

The increment of the strain vector with the dependencies $\Delta \mathrm{u}$ and $\Delta \mathrm{g}$ taken into account takes the form:

$$
\Delta \varepsilon=\mathbf{B}_{0} \Delta \mathbf{q}+\mathbf{B}_{1}(\mathbf{g}) \Delta \mathbf{q}+\frac{1}{2} \mathbf{B}_{1}(\Delta \mathbf{g}) \Delta \mathbf{q}
$$

where:

$$
\begin{gathered}
\mathbf{B}_{0}=\left[\begin{array}{cccccc}
-\frac{1}{1} & 0 & 0 & \frac{1}{1} & 0 & 0 \\
0 & \frac{6(1-2 \xi)}{1} & \frac{2(2-3 \xi)}{1} & 0 & \frac{-6(1-2 \xi)}{1^{2}} & \frac{2(1-3 \xi)}{1}
\end{array}\right] \\
\mathbf{B}_{1}(\mathbf{g})=\mathbf{v}^{\prime}\left[\begin{array}{cccccc}
0 & \frac{-6 \xi(1-\xi)}{1} & 1-4 \xi+3 \xi^{2} & 0 & \frac{6 \xi(1-\xi)}{1} & -\xi(2-3 \xi) \\
0 & 0 & 0 & 0 & 0 & 0
\end{array}\right]
\end{gathered}
$$

The tangent stiffness matrix used in the incremental equilibrium equations of the frame element is presented as follows.

$$
\mathbf{K}_{\mathrm{T}}=\mathbf{K}_{\mathrm{L}}+\mathbf{K}_{\mathrm{u} 1}+\mathbf{K}_{\mathrm{u} 2}+\mathbf{K}_{\mathrm{G}}
$$




$$
\begin{aligned}
& \mathbf{K}_{\mathrm{L}}=\left[\begin{array}{cccccc}
\frac{\mathrm{EA}}{1} & 0 & 0 & \frac{\mathrm{EA}}{1} & 0 & 0 \\
0 & \frac{12 \mathrm{EI}}{1^{3}} & \frac{6 \mathrm{EI}}{1^{2}} & 0 & \frac{-12 \mathrm{EI}}{1^{3}} & \frac{6 \mathrm{EI}}{1^{2}} \\
0 & \frac{6 \mathrm{EI}}{1^{2}} & \frac{4 \mathrm{EI}}{1} & 0 & \frac{6 \mathrm{EI}}{1^{2}} & \frac{2 \mathrm{EI}}{1} \\
\frac{-\mathrm{EA}}{1} & 0 & 0 & \frac{\mathrm{EA}}{1} & 0 & 0 \\
0 & \frac{12 \mathrm{EI}}{3^{3}} & \frac{-6 \mathrm{EI}}{1^{2}} & 0 & \frac{12 \mathrm{EI}}{1^{3}} & \frac{6 \mathrm{EI}}{1^{2}} \\
0 & \frac{6 \mathrm{EI}}{1^{2}} & \frac{2 \mathrm{EI}}{1} & 0 & \frac{-6 \mathrm{EI}}{1^{2}} & \frac{4 \mathrm{EI}}{1}
\end{array}\right] \\
& \mathbf{K}_{\mathrm{G}}=-\mathrm{S}\left[\begin{array}{cccccc}
0 & 0 & 0 & 0 & 0 & 0 \\
0 & \frac{6}{51} & \frac{1}{10} & 0 & \frac{-6}{51} & \frac{1}{10} \\
0 & \frac{1}{10} & \frac{21}{15} & 0 & \frac{-1}{10} & \frac{1}{30} \\
0 & 0 & 0 & 0 & 0 & 0 \\
0 & \frac{-6}{51} & \frac{-1}{10} & 0 & \frac{6}{51} & \frac{-1}{10} \\
0 & \frac{1}{10} & \frac{-1}{30} & 0 & \frac{-1}{10} & \frac{21}{15}
\end{array}\right] \\
& \begin{array}{c}
\mathbf{K}_{\mathrm{u} 1}=\operatorname{EA1}\left[\int_{0}^{1}\left[\begin{array}{ccccccc}
0 & -\mathrm{v}^{\prime} \cdot \Gamma_{2} & -\mathrm{v}^{\prime} \cdot \Gamma_{3} & 0 & -\mathrm{v}^{\prime} \cdot \Gamma_{5} & -\mathrm{v}^{\prime} \cdot \Gamma_{6} \\
-\mathrm{v}^{\prime} \cdot \Gamma_{2} & 0 & 0 & \mathrm{v}^{\prime} \cdot \Gamma_{2} & 0 & 0 \\
-\mathrm{v}^{\prime} \cdot \Gamma_{3} & 0 & 0 & \mathrm{v}^{\prime} \cdot \Gamma_{3} & 0 & 0 \\
0 & \mathrm{v}^{\prime} \cdot \Gamma_{2} & \mathrm{v}^{\prime} \cdot \Gamma_{3} & 0 & \mathrm{v}^{\prime} \cdot \Gamma_{5} & \mathrm{v}^{\prime} \cdot \Gamma_{6} \\
-\mathrm{v}^{\prime} \cdot \Gamma_{5} & 0 & 0 & \mathrm{v}^{\prime} \cdot \Gamma_{5} & 0 & 0 \\
-\mathrm{v}^{\prime} \cdot \Gamma_{6} & 0 & 0 & \mathrm{v}^{\prime} \cdot \Gamma_{6} & 0 & 0
\end{array}\right] \mathrm{d} \xi\right] \\
\mathbf{K}_{\mathrm{u} 2}=\operatorname{EAl}\left[\int_{0}^{1}\left[\begin{array}{ccccccc}
0 & 0 & 0 & 0 & 0 & 0 \\
0 & \mathrm{v}^{2} \cdot \Gamma_{2}^{2} & \mathrm{v}^{2} \cdot \Gamma_{2} \cdot \Gamma_{3} & 0 & \mathrm{v}^{2} \cdot \Gamma_{2} \cdot \Gamma_{5} & \mathrm{v}^{2} \cdot \Gamma_{2} \cdot \Gamma_{6} \\
0 & \mathrm{v}^{2} \cdot \Gamma_{3} \cdot \Gamma_{2} & \mathrm{v}^{2} \cdot \Gamma_{3}^{2} & 0 & \mathrm{v}^{2} \cdot \Gamma_{5} \cdot \Gamma_{3} & \mathrm{v}^{2} \cdot \Gamma_{3} \cdot \Gamma_{6} \\
0 & 0 & 0 & 0 & 0 & 0 \\
0 & \mathrm{v}^{2} \cdot \Gamma_{5} \cdot \Gamma_{2} & \mathrm{v}^{2} \cdot \Gamma_{5} \cdot \Gamma_{3} & 0 & \mathrm{v}^{2} \cdot \Gamma_{5}^{2} & \mathrm{v}^{2} \cdot \Gamma_{5} \cdot \Gamma_{6} \\
0 & \mathrm{v}^{2} \cdot \Gamma_{6} \cdot \Gamma_{2} & \mathrm{v}^{2} \cdot \Gamma_{6} \cdot \Gamma_{3} & 0 & \mathrm{v}^{2} \cdot \Gamma_{6} \cdot \Gamma_{5} & \mathrm{v}^{2} \cdot \Gamma_{6}^{2}
\end{array}\right] \mathrm{d} \xi\right]
\end{array}
\end{aligned}
$$

\section{Results}

\subsection{Example 1}

\subsubsection{Von Mises Truss Analysis}

Two cases of von Mises truss differing in the height-to-span ratio were considered. Figure 6 shows the structure geometry for both cases.

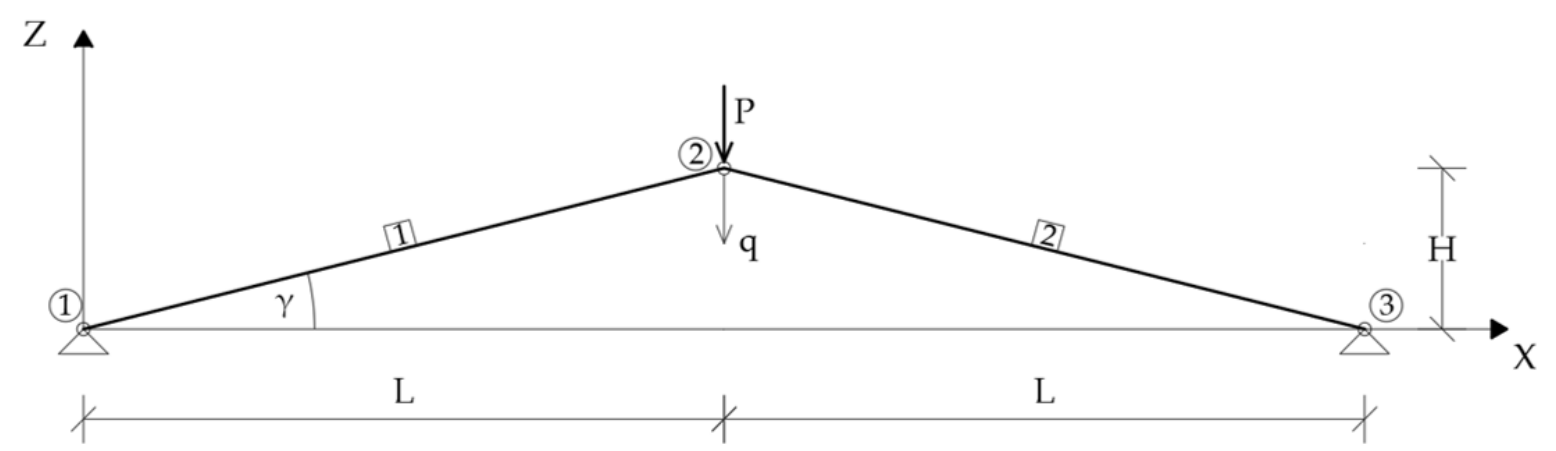

Figure 6. Von Mises truss geometry.

\section{Case 1-High Truss}

The von Mises truss with a span of $\mathrm{L}=4.0 \mathrm{~m}$ and a height of $\mathrm{H}=1.0 \mathrm{~m}$, loaded with a force of $\mathrm{P}=10 \mathrm{kN}$, was modelled with steel pipes RO60.3 $\times 4$, with a yield strength of $\mathrm{f}_{\mathrm{y}}=235 \mathrm{MPa}$; Young modulus $\mathrm{E}=210 \mathrm{GPa}$; and Poissons ratio $\mathrm{v}=0.3$. The height-to-span ratio is $\mathrm{H} / \mathrm{L}=0.25$, and the bar 
angle is $\gamma=14^{\circ}$. The lengths of both elements are $1_{0}=412.3 \mathrm{~cm}$. The values of the axial force in the bar and the vertical displacement of node 2, determined on the basis of LA (linear analysis) and GNA, do not differ significantly (Table 1).

Table 1. Values of axial force and nodal displacement.

\begin{tabular}{ccc}
\hline Force/Displacement/Analysis & LA & GNA \\
\hline Axial force & $20.616 \mathrm{kN}$ & $20.660 \mathrm{kN}$ \\
Nodal displacement of node No. 2 & $0.236 \mathrm{~cm}$ & $0.237 \mathrm{~cm}$ \\
\hline
\end{tabular}

The value of the determinant of the tangent $\operatorname{det}\left(\mathrm{K}_{\mathrm{T}}\right)$ stiffness matrix of the structure in the case of geometrically nonlinear analysis is $0.2851 \times 10^{9}$, while in the linear analysis, $0.2872 \times 10^{9}$. The value of the current stiffness parameter (CSP) practically did not change. In the linear analysis, this value was 1.0, while in the geometrically nonlinear analysis, 0.9929 . The critical load multiplier obtained from the LBA analysis is $\mu_{\mathrm{cr}}=423.638$. According to the recommendations of the PN-EN-1993-1-1 [3] standard, for a critical multiplier value $\mu>10$, a linear analysis is sufficient.

Figure $7 \mathrm{a}$ shows the equilibrium path for the von Mises truss case under consideration, while Figure $7 \mathrm{~b}$ shows the CSP-q dependency graph.

a)

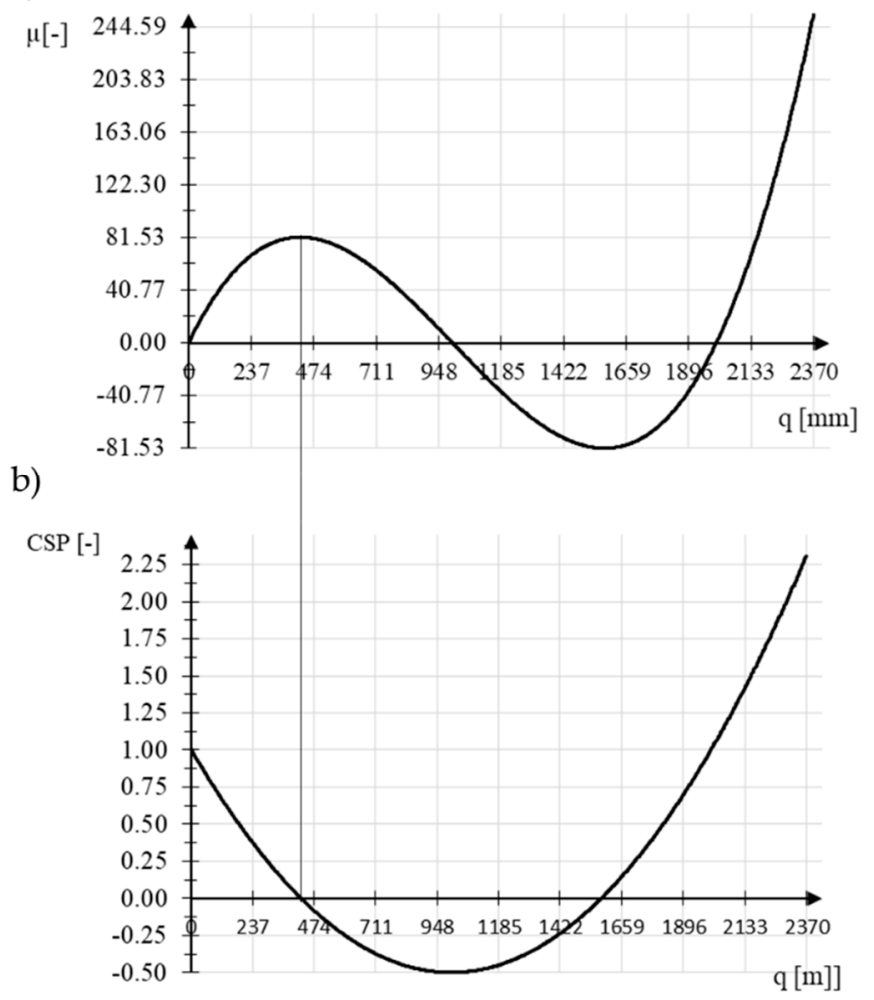

Figure 7. (a) Equilibrium path of high von Mises truss, (b) CSP-q path of high von Mises truss.

Case 2-Shallow Truss

In the second case, a structure with a span of $\mathrm{L}=4.0 \mathrm{~m}$ and a height of $\mathrm{H}=0.2 \mathrm{~m}$, loaded with a force of $\mathrm{P}=10 \mathrm{kN}$, was considered. The structure was modelled from $\mathrm{RO} 76.1 \times 8$ steel pipes with a yield strength of $\mathrm{f}_{\mathrm{y}}=235 \mathrm{MPa}$; Young's modulus $\mathrm{E}=210 \mathrm{GPa}$; and Poissons ratio $\mathrm{v}=0.3$. The height-to-span ratio is $\mathrm{H} / \mathrm{L}=0.05$ and the bar angle $\gamma=3^{\circ}$. The lengths of both elements are $1_{0}=400.5 \mathrm{~cm}$.

The values of the axial force and the vertical displacement of node 2 , determined on the basis of LA and GNA, differ significantly (Table 2). 
Table 2. Values of axial force and nodal displacement.

\begin{tabular}{ccc}
\hline Force/Displacement/Analysis & LA & GNA \\
\hline Axial force & $100.125 \mathrm{kN}$ & $116.6 \mathrm{kN}$ \\
Nodal displacement of node No. 2 & $2.236 \mathrm{~cm}$ & $2.795 \mathrm{~cm}$ \\
\hline
\end{tabular}

The value of the determinant of the tangent det $\left(\mathrm{K}_{\mathrm{T}}\right)$ stiffness matrix of the structure for geometrically nonlinear analysis is $0.4977 \times 10^{8}$, while for linear analysis, $0.7999 \times 10^{8}$. The value of the current stiffness parameter decreased significantly. In the linear analysis, this value was 1.0, while in the geometrically nonlinear analysis, 0.6223 . The critical load multiplier obtained from the LBA is $\mu_{\mathrm{cr}}=8.944$. According to the recommendations of the PN-EN-1993-1-1 [3] standard, for a critical multiplier value $\mu<10$, a more accurate geometrically nonlinear structure analysis is recommended. The results obtained clearly confirm the entries in the Eurocode. In the second example, we will use them consistently.

Figure $8 \mathrm{a}$ shows the equilibrium path for the von Mises truss case under consideration, while Figure $8 \mathrm{~b}$ shows the CSP-q dependency graph.

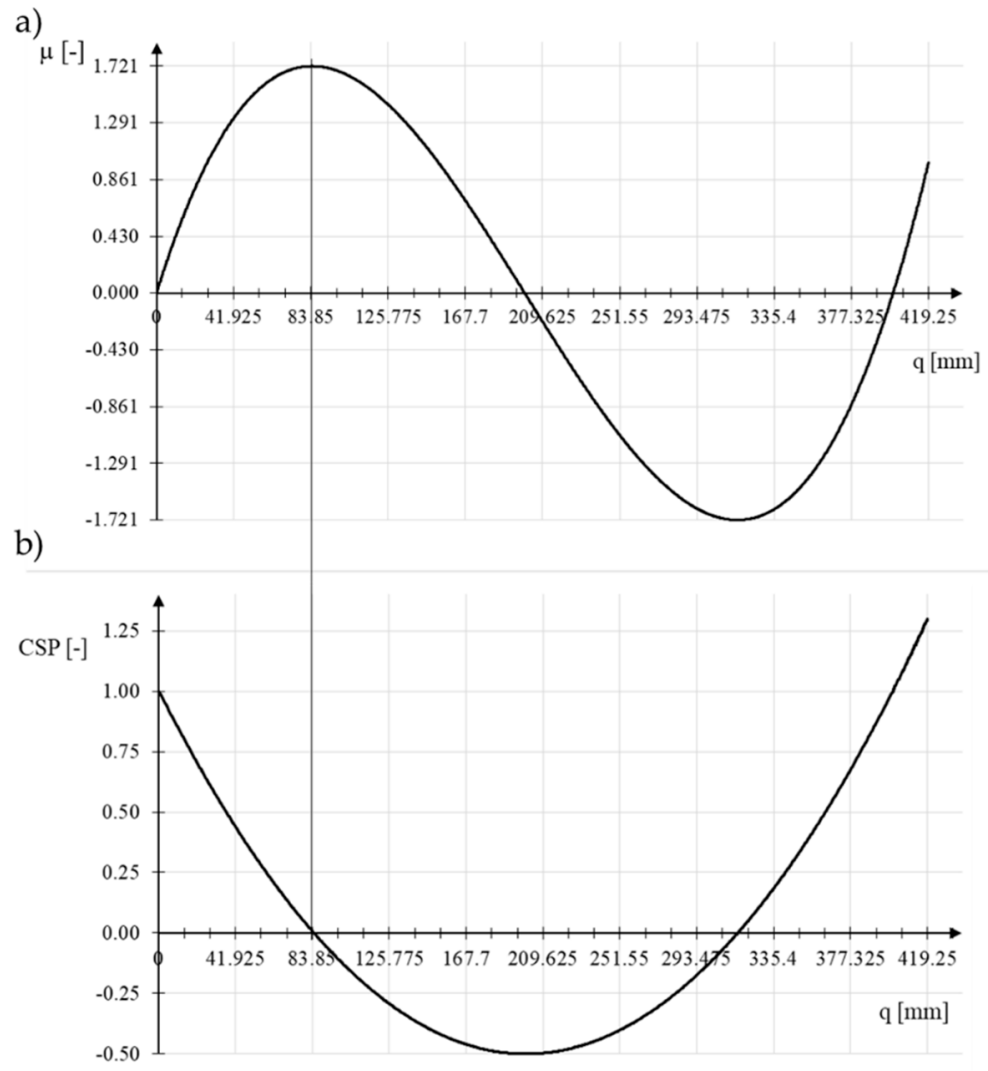

Figure 8. (a) Equilibrium path of shallow von Mises truss, (b) CSP-q path of shallow von Mises truss.

\subsubsection{Discussion of Example 1}

Based on the analyses carried out, a significant impact of structure geometry on the values of axial forces and displacements of the structure node was observed. In both cases, examples of the equilibrium path of von Mises trusses and the corresponding CSP-q path were presented.

In the first case, the structure with a height-to-span ratio of 0.25 was not susceptible to geometric nonlinearities. The difference in axial forces and displacements between linear and geometrically nonlinear analysis was below $1 \%$. The change value of the stiffness matrix determinant also proved to be insignificant. 
For shallow structures, changes in axial forces and displacements turned out to be significant. The axial force value increased from $100.125 \mathrm{kN}$ obtained in a linear analysis to $116.6 \mathrm{kN}$ in a geometrically nonlinear analysis.

Similarly, the values of the displacement of the second node changed from 2.236 to $2.795 \mathrm{~cm}$. There was also a significant change in the value of the stiffness matrix determinant and the current stiffness parameter.

A similar tendency in the behavior of the structure can be observed on fragments of larger structures, including shallow single-layer steel domes (Figure 9). Example 2 describes these problems.

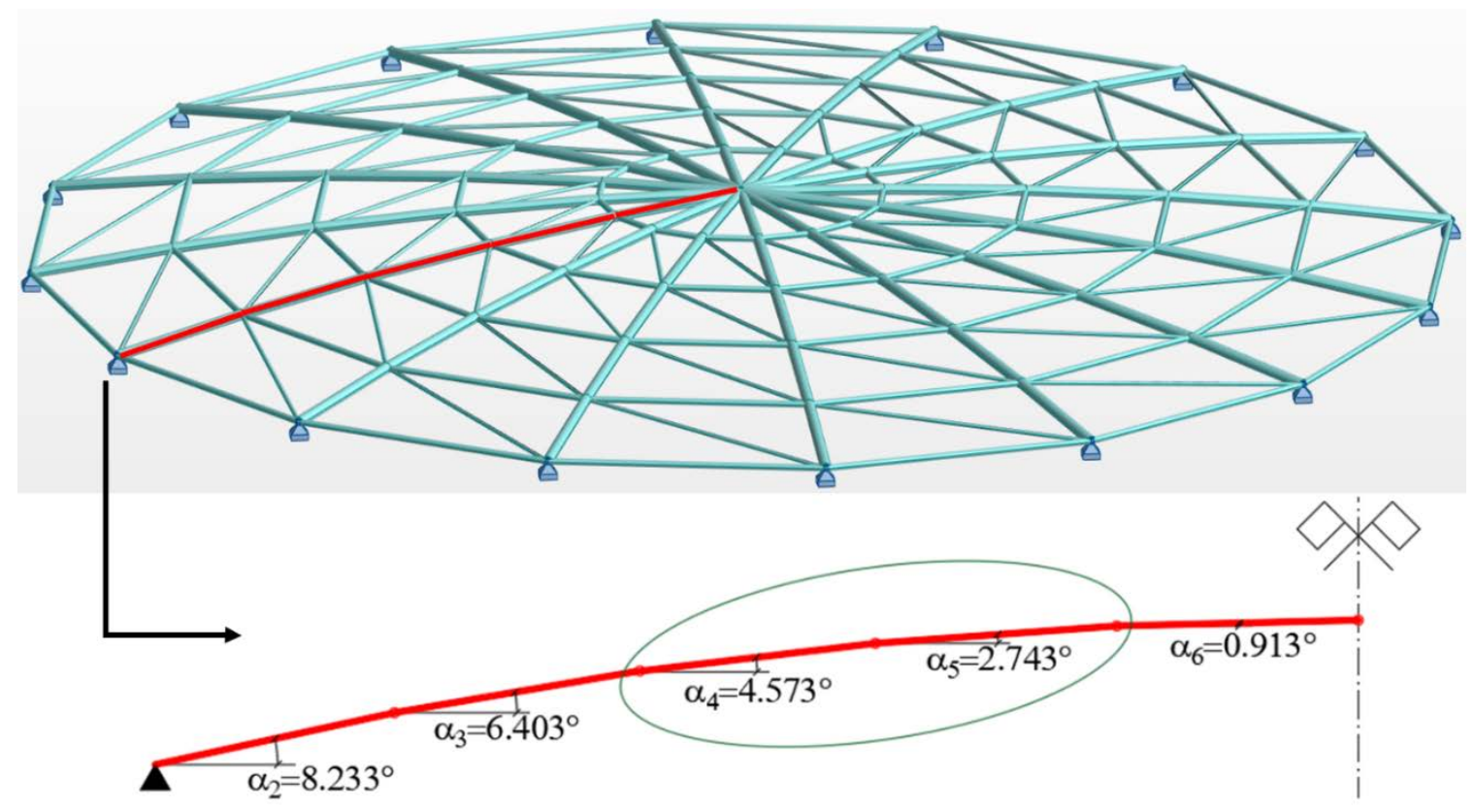

Figure 9. Example of shallow dome.

\subsection{Example 2}

\subsubsection{Geometry and Loads}

The dome with the diameter of $25 \mathrm{~m}$ and height of $1 \mathrm{~m}$ will top the building housing a restaurant. The location, a village of Święta Katarzyna, lies in the Świętokrzyskie Mountains.

The structure is based on 16 reinforced concrete columns, $5 \mathrm{~m}$ high. The whole structure is closed with a reinforced concrete wreath forming a rigid structure, which simulates grillages work.

A mesh of the dome consisting of 81 nodes and 224 elements is illustrated in Figure 10. The most-stressed elements of the groups, and the nodes with the most displacement in GNA, are marked on Figure 10, case 1 by green and case 2 by red color. The structure of concern is Schwedler type bar dome. The length of each meridian is $2.511 \mathrm{~m}$. Parallels become shorter as the dome tapers up; the successive lengths, starting at the base, are: $4.877,3.908,2.934,1.958$, and $0.979 \mathrm{~m}$. The covering will comprise tubular steel bars and glass panels. 

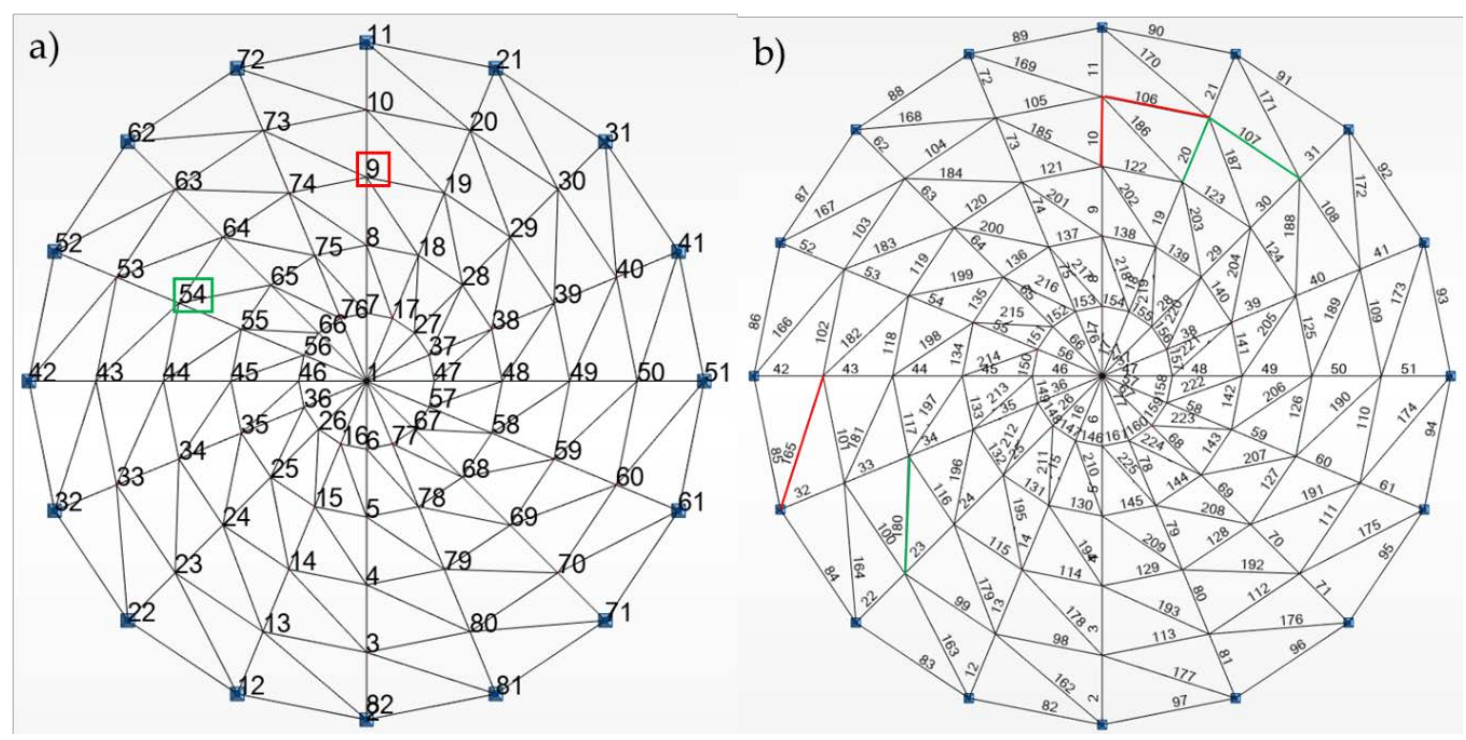

Figure 10. Schwedler dome geometry: (a) nodes, (b) elements (by green-case 1; by red-case 2).

For the dome of concern, the following loads were assumed: permanent load-G (self-weight of the bar structure and the covering); snow load-S for zone 3 (acc. PN-EN 1991-1-3 [38]); wind load-W (acc. PN-EN 1991-1-4) [39]. The combination of loads applied to the structure was in compliance with PN-EN 1990 [40]. Evenly distributed loads were reduced to concentrated forces applied in all nodes. The load is concentrated to nodes according to the load distribution regions (envelope distribution).

To facilitate the description of analysis concerning a structure with a large number of nodes, the nodes located on subsequent rings were grouped. Table 3 shows the grouping of nodes into clusters R1-R5. Furthermore, loads applied to a group of nodes are given, which means each node of a given cluster is under the same load. The keystone (node no 1) does not belong to any of the groups.

Table 3. Groups of nodes and the corresponding node numbers.

\begin{tabular}{cc}
\hline Group Name & Numbers of Nodes \\
\hline R1 & $6,16,26,36,46,56,66,76,7,17,27,37,47,57,67,77$ \\
R2 & $5,15,25,35,45,55,65,75,8,18,28,38,48,58,68,78$ \\
R3 & $4,14,24,34,44,54,64,74,9,19,29,39,49,59,69,79$ \\
R4 & $3,13,23,33,43,53,63,73,10,20,30,40,50,60,70,80$ \\
R5 & $2,12,22,32,42,52,62,72,11,21,31,41,51,61,71,81$ \\
\hline
\end{tabular}

The average characteristic value of the dome's own weight was assumed to be $1.45 \mathrm{kN} / \mathrm{m}^{2}$. The permanent load values for individual groups of nodes are summarized in Table 4 .

Table 4. Dome's own weight reduced to concentrated forces at the nodes.

\begin{tabular}{cc}
\hline Nodes Group & Own Weight Load Value-G (kN) \\
\hline R1 & 3.564 \\
R2 & 7.129 \\
R3 & 10.683 \\
R4 & 14.229 \\
R5 & 8.878 \\
Node No. 1 & 7.180 \\
\hline
\end{tabular}

The average characteristic value of the snow load was determined based on the standard [38]. The structure of concern is located in the Świętokrzyskie Mountains at the height of A $=530 \mathrm{~m}$ amsl, 
which is the snow load in zone 3. For the considered structure, the characteristic value of roof snow load is: $\mathrm{s}=1.651 \mathrm{kN} / \mathrm{m}^{2}$. The snow load values for individual groups of nodes are summarized in Table 5 .

Table 5. Dome loaded with uniform snow load represented as concentrated forces.

\begin{tabular}{cc}
\hline Nodes Group & Snow Load Value-S (kN) \\
\hline R1 & 4.059 \\
R2 & 8.118 \\
R3 & 12.165 \\
R4 & 16.203 \\
R5 & 10.110 \\
Node No. 1 & 8.176 \\
\hline
\end{tabular}

For low-rise structures (flat roofs) for which the $\mathrm{f} / \mathrm{d}$ ratio $<0.05$, wind load is usually neglected. This is due to the common belief that consideration of wind has a positive effect on the values of cross-sectional forces of the bars. In the considered work, it was decided to present an example scheme for collecting wind load on a shallow bar dome and to verify the impact of uneven wind suction loading on structural behavior.

Unlike forces of dead load and snow load, the wind force acts perpendicular to the roof surface. As the structure of concern is a double-curved bar dome, it is necessary to determine angles of inclination of individual meridians $-\alpha_{n}$-in order to specify the wind force deviation from the vertical axis " $\mathrm{z}$ " $-\delta_{\mathrm{n}}$. The values of angles $\alpha_{\mathrm{n}}$ and $\delta_{\mathrm{n}}$ are shown in Figure 11. The dome is divided by meridians into 16 equal parts. The angle $\gamma$ by which the wind force in the XY plane should be rotated is $\gamma=360 / 16=22.5^{\circ}$.

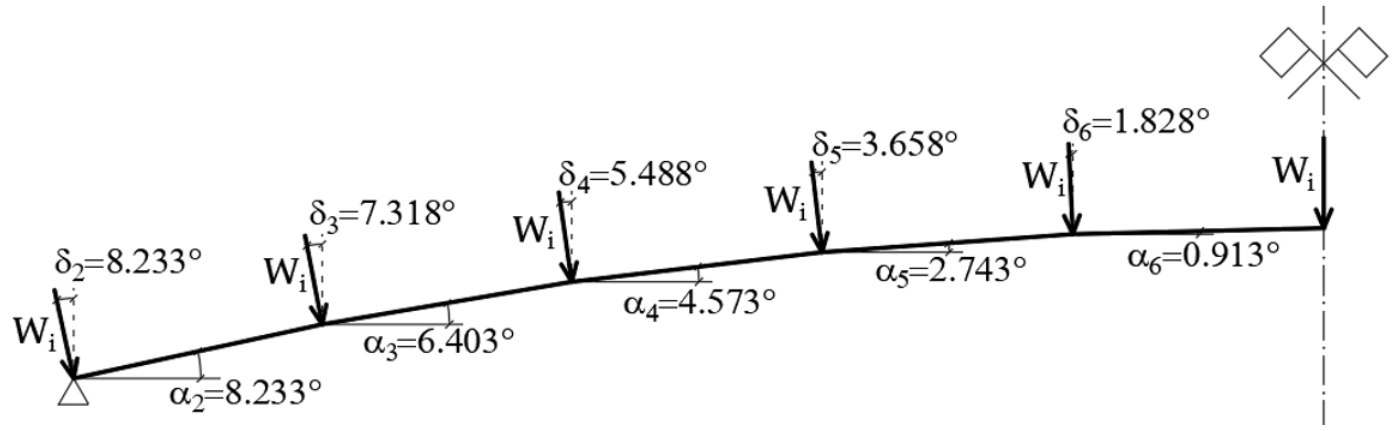

Figure 11. The values of angles $\alpha_{\mathrm{n}}$ and $\delta_{\mathrm{n}}$.

When calculating wind pressure coefficient, the standards applied were in accordance with [39]. The wind load distribution recommended by the standard is based on the assumption that on the dome arch determined by cutting the dome with a vertical plane perpendicular to the direction of the wind, the pressure is constant (broken lines in Figure 12).

To determine the external pressure coefficients for the dome of concern, it is necessary to determine the following Equations (25) and (26):

$$
\begin{aligned}
& \frac{\mathrm{h}}{\mathrm{d}}=\frac{5 \mathrm{~m}}{25 \mathrm{~m}}=0.20 \\
& \frac{\mathrm{f}}{\mathrm{d}}=\frac{1 \mathrm{~m}}{25 \mathrm{~m}}=0.04
\end{aligned}
$$

For the $\mathrm{h} / \mathrm{d}$ Equation (25), the $\mathrm{C}_{\mathrm{pe}, \mathrm{A}}, \mathrm{C}_{\mathrm{pe}, \mathrm{B}}$, and $\mathrm{C}_{\mathrm{pe}, \mathrm{C}}$ coefficients can be determined by linear interpolation of the data value in the graph in Figure 13 as a function of the f/d Equation (26). 

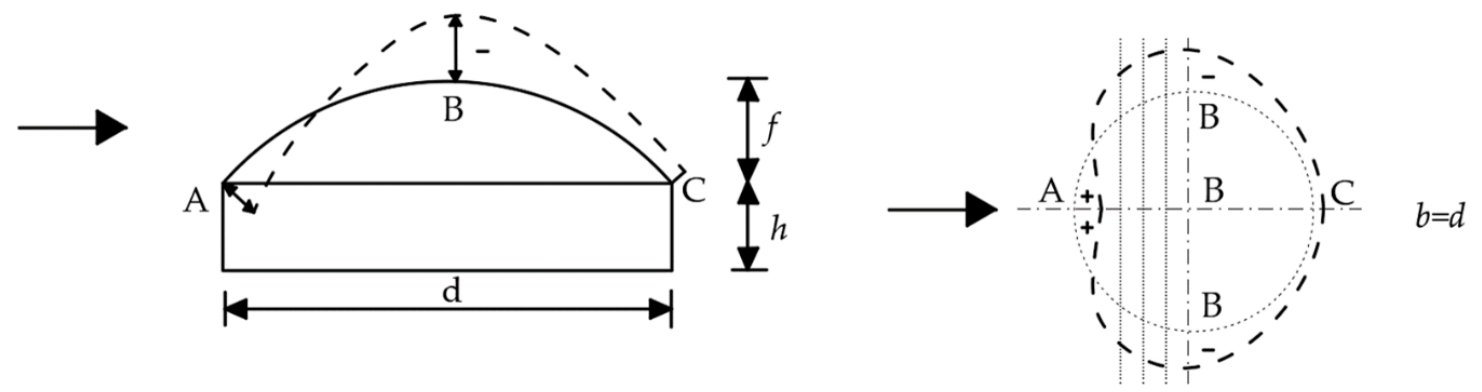

Figure 12. Diagram of the structure division into wind zones acc. [39].

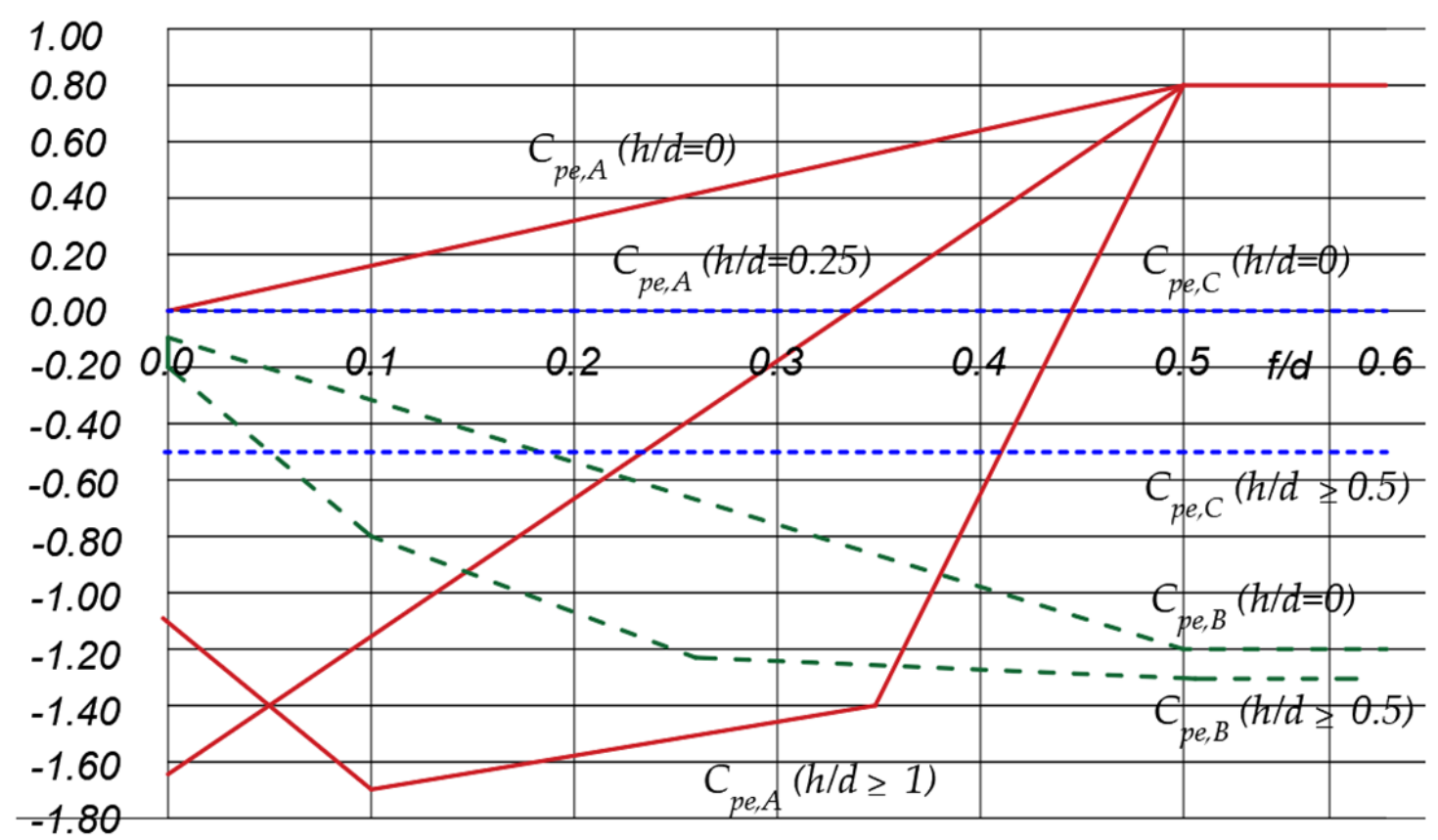

Figure 13. Values of Cpe,i (i = A—red; B—green; C—blue) coefficients for dome structure acc. [39].

Based on Figure 13, the relationship (27) necessary for interpolation of $C_{p e, i}$ indices was determined:

$$
\mathrm{y}_{\mathrm{n}}=\frac{\mathrm{y}_{2}-\mathrm{y}_{1}}{\mathrm{x}_{2}-\mathrm{x}_{1}} \cdot\left(\frac{\mathrm{f}}{\mathrm{d}}-\mathrm{x}_{1}\right)+\mathrm{y}_{1}
$$

For values of: $\mathrm{h} / \mathrm{d}=0.20$ and $\mathrm{f} / \mathrm{d}=0.04$, the following were obtained: $\mathrm{C}_{\mathrm{pe}, \mathrm{A}}=-1.14 ; \mathrm{C}_{\mathrm{pe}, \mathrm{B}}=-0.56$; $\mathrm{C}_{\mathrm{pe}, \mathrm{C}}=-0.20$.

The considered dome was divided into the wind load zones as shown in Figure 14.

On the basis of Figure 15, the relationship 28, necessary for interpolation of the wind pressure coefficient at the designated points (Table 6), was determined.

$$
\frac{C_{p e, A}-C_{p e, n}}{x_{n}-x_{A}}=\frac{C_{p e, A}-C_{p e, B}}{x_{B}-x_{A}} .
$$




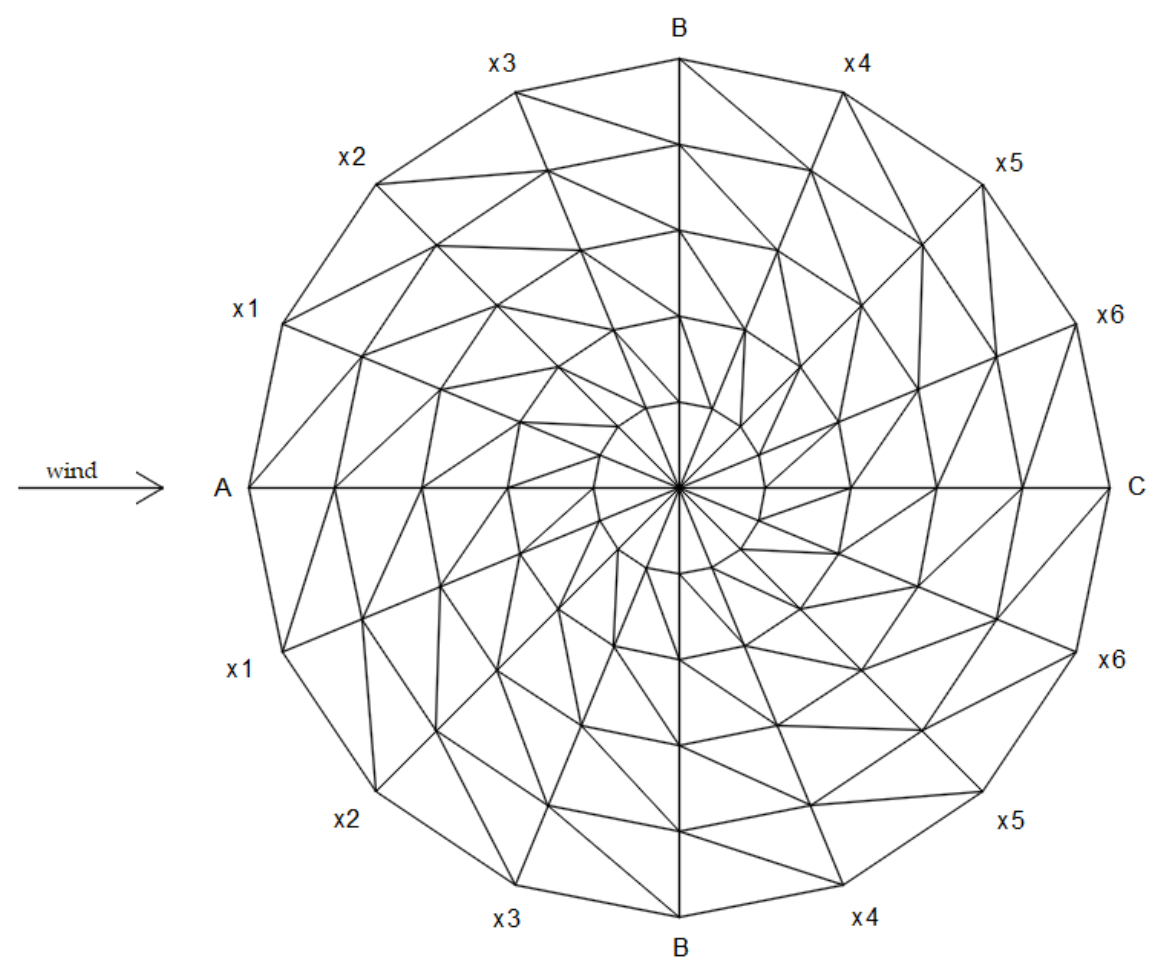

Figure 14. Wind zones of the dome.

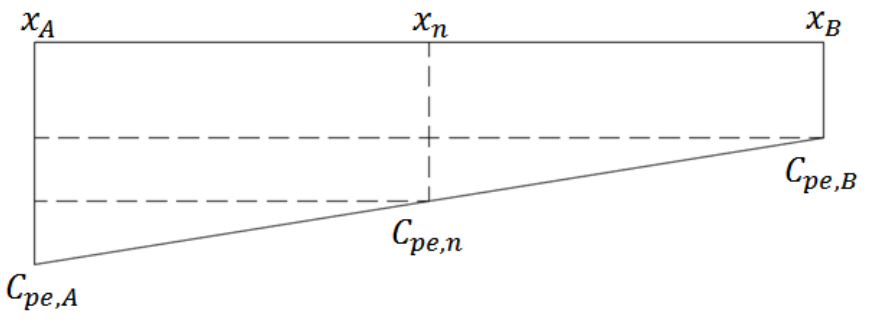

Figure 15. Wind pressure coefficient interpolation scheme.

Table 6. Interpolated values of wind pressure coefficients.

\begin{tabular}{cccccccccc}
\hline Pressure Coefficients & $\mathbf{x}_{\mathbf{A}}$ & $\mathbf{x}_{\mathbf{1}}$ & $\mathbf{x}_{\mathbf{2}}$ & $\mathbf{x}_{\mathbf{3}}$ & $\mathbf{x}_{\mathbf{B}}$ & $\mathbf{x}_{\mathbf{4}}$ & $\mathbf{x}_{\mathbf{5}}$ & $\mathbf{x}_{\mathbf{6}}$ & $\mathbf{x}_{\mathbf{C}}$ \\
\hline $\mathrm{x}$ & 0.00 & 3.125 & 6.25 & 9.375 & 12.50 & 15.625 & 18.75 & 21.875 & 25.00 \\
$\mathrm{C}_{\mathrm{pe}}$ & -1.14 & -1.00 & -0.85 & -0.71 & -0.56 & -0.47 & -0.38 & -0.29 & -0.20 \\
\hline
\end{tabular}

After determining the pressure coefficients, the pressure of the wind on the dome was determined acc. standard [39]. For domes, it is necessary to determine the reference height that is significant when determining the wind load. The reference height of the dome in question is: $\bar{z}_{\mathrm{e}}=\mathrm{h}+\frac{\mathrm{f}}{2}=5 \mathrm{~m}+\frac{1}{2} \mathrm{~m}=5.5 \mathrm{~m}$ the base wind speed is $\mathrm{v}_{\mathrm{b}, 0}=25.04 \mathrm{~m} / \mathrm{s}$; while the exposure factor is: $c_{e}\left(\bar{z}_{e}\right)=1.99$. The base value of the wind speed pressure was determined on the level $\mathrm{q}_{\mathrm{b}}=0.392 \mathrm{kN} / \mathrm{m}^{2}$. The peak value of pressure wind speed is equal to $\mathrm{q}_{\mathrm{p}}\left(\overline{\mathrm{z}}_{\mathrm{e}}\right)=0.392 \cdot 1.99=0.780 \mathrm{kN} / \mathrm{m}^{2}$.

The values of wind load in individual nodes are obtained from multiplication of the peak value of wind speed pressure, wind pressure coefficient, meridian length values, and length values of individual parallels. The results for the sequentially numbered nodes are summarized in Table 7. 
Table 7. Values of the wind load to the individual nodes.

\begin{tabular}{cccccccc}
\hline $\begin{array}{c}\text { Node } \\
\text { Number }\end{array}$ & $\begin{array}{c}\text { Wind Load } \\
\text { Value } \\
\mathbf{( k N )}\end{array}$ & $\begin{array}{c}\text { Node } \\
\text { Number }\end{array}$ & $\begin{array}{c}\text { Wind Load } \\
\text { Value } \\
\mathbf{( k N )}\end{array}$ & $\begin{array}{c}\text { Node } \\
\text { Number }\end{array}$ & $\begin{array}{c}\text { Wind Load } \\
\text { Value } \\
\mathbf{( k N )}\end{array}$ & $\begin{array}{c}\text { Node } \\
\text { Number }\end{array}$ & $\begin{array}{c}\text { Wind Load } \\
\text { Value } \\
\mathbf{( k N )}\end{array}$ \\
\hline 1 & -2.588 & 21 & -1.385 & 41 & -2.245 & 61 & -3.391 \\
2 & -5.445 & 22 & -4.06 & 42 & -2.675 & 62 & -1.815 \\
3 & -8.726 & 23 & -6.506 & 43 & -4.286 & 63 & -2.909 \\
4 & -6.551 & 24 & -4.885 & 44 & -3.218 & 64 & -2.184 \\
5 & -4.372 & 25 & -3.26 & 45 & -2.148 & 65 & -1.457 \\
6 & -2.186 & 26 & -1.63 & 46 & -1.074 & 66 & -0.729 \\
7 & -0.383 & 27 & -0.729 & 47 & -1.074 & 67 & -1.63 \\
8 & -0.767 & 28 & -1.457 & 48 & -2.148 & 68 & -3.26 \\
9 & -1.149 & 29 & -2.184 & 49 & -3.218 & 69 & -4.885 \\
10 & -1.5311 & 30 & -2.909 & 50 & -4.286 & 70 & -6.506 \\
11 & -0.955 & 31 & -1.815 & 51 & -2.675 & 71 & -4.06 \\
12 & -4.7766 & 32 & -3.391 & 52 & -2.245 & 72 & -1.385 \\
13 & -7.654 & 33 & -5.434 & 53 & -3.597 & 73 & -2.22 \\
14 & -5.746 & 34 & -4.08 & 54 & -2.701 & 74 & -1.666 \\
15 & -3.835 & 35 & -2.723 & 55 & -1.802 & 75 & -1.112 \\
16 & -1.917 & 36 & -1.361 & 56 & -0.901 & 76 & -0.556 \\
17 & -0.556 & 37 & -0.901 & 57 & -1.361 & 77 & -1.917 \\
18 & -1.112 & 38 & -1.802 & 58 & -2.723 & 78 & -3.835 \\
19 & -1.666 & 39 & -2.701 & 59 & -4.08 & 79 & -5.746 \\
20 & -2.22 & 40 & -3.597 & 60 & -5.434 & 80 & -7.654 \\
& & & - & & & 81 & -4.776 \\
\hline
\end{tabular}

\subsubsection{Case 1. Load Combination: $1.15 \mathrm{G}+1.5 \mathrm{~S}$}

In the first case, the situation of a standard approach to the dimensioning of shallow structures (flat roofs) was considered.

For the dome of concern, the following loads were assumed: permanent load $-\mathrm{G}$ (self-weight of the bar structure and the covering); snow load-S for zone 3 (acc. [38]).

The static-strength analysis, intended to produce the dimensioning of the steel elements, was performed acc. PN-EN-1993-1-1 [3] using Autodesk Robot Structure Professional 2019 software for spatial frame structure. To increase the accuracy of calculations, all the elements were additionally divided into 10 parts. The elements of the structure were assumed to be made of steel tubes with yield point $\mathrm{f}_{\mathrm{y}}=235 \mathrm{MPa}$ and Young's modulus $\mathrm{E}=210 \mathrm{GPa}$; Poisson's ratio $\mathrm{v}=0.3$. In order to dimension the designed structure, three groups of rods were modeled: meridians, parallels, and diagonals.

The values of cross-sectional forces, load capacity for the most-stressed elements of these groups, and the displacement limits of node 79 are summarized in Table 8. The cross-sections taken for different groups of rods are summarized in Table 9. Figure 16 shows the deformation of the structure.

In the second step, the considered structure was subjected to linear buckling analysis. The lowermost critical load multiplier is equal to $\mu_{\mathrm{cr}}=2.11199$. Figure 17 shows the buckling modes for four successive eigenvalues. According to PN EN 1993-1-1/5.2.2 (5)B [3], when the lowermost critical load multiplier $\mu_{\mathrm{cr}}<3.0$, it is necessary to carry out a more accurate second order (GNA) analysis for the structure.

In the last step, the geometrically nonlinear static analysis was carried out. Nonlinear analysis produced the results of displacements and internal forces while taking into account second-order effects. In GNA, the lowermost critical load multiplier is equal to $\mu_{\mathrm{cr}}=1.562$. Exceeding this multiplier results in a peculiar stiffness matrix. GNA is a mathematical tool with which it is possible to generate complete equilibrium paths. Tracking the equilibrium path is inherently related to the analysis of post-critical states. The problem presented in example 2 concerns the design of a real shallow steel lattice structure. These types of structures are susceptible to large displacement gradients, which can only be considered by using geometrically nonlinear relationships. GNA in this case is used to determine the internal 
forces, displacements, and critical load multiplier. In the case of the analyzed shallow lattice dome, the critical load is related to the phenomenon of the node snap-through. After the critical load is exceeded, only unstable equilibrium states occur. From an engineering point of view, the part of the equilibrium path after reaching the critical load multiplier does not cause significant changes to the structure design process. Figure 18 shows the equilibrium path of the considered bar dome for case 1 .

Table 8. Values of the internal forces and the maximum horizontal and vertical displacement of node 79 for LA.

\begin{tabular}{|c|c|c|c|}
\hline \multirow[b]{2}{*}{ Internal Forces/Displacement } & \multicolumn{3}{|c|}{ LA } \\
\hline & $\begin{array}{l}\text { Meridian } \\
\text { Bar no } 30\end{array}$ & $\begin{array}{c}\text { Parallel } \\
\text { Bar no } 114\end{array}$ & $\begin{array}{c}\text { Diagonal } \\
\text { Bar no } 193\end{array}$ \\
\hline $\mathrm{N}_{\mathrm{Ed}}(\mathrm{kN})$-axial force & 563.694 & 162.79 & 1.977 \\
\hline $\begin{array}{c}\mathrm{N}_{\mathrm{c}, \mathrm{Rd}}(\mathrm{kN}) \text { - design capacity of the section under uniform } \\
\text { compression }\end{array}$ & 1543.95 & 552.250 & 212.910 \\
\hline $\mathrm{N}_{\mathrm{b}, \mathrm{Rd}}(\mathrm{kN})$ - design buckling resistance of the compressed element & 1486.389 & 275.405 & 60.072 \\
\hline $\mathrm{M}_{\mathrm{y}, \mathrm{Ed}, \operatorname{Max}}(\mathrm{kNm})$-design bending moment with respect to $\mathrm{y}-\mathrm{y}$ axis & 28.537 & 0.569 & 0.316 \\
\hline $\mathrm{M}_{\mathrm{y}, \mathrm{c}, \mathrm{Rd}}(\mathrm{kNm})$ - design bending resistance with respect to $\mathrm{y}-\mathrm{y}$ axis & 102.827 & 16.511 & 4.892 \\
\hline $\mathrm{M}_{\mathrm{z}, \mathrm{Ed}, \max }(\mathrm{kNm})$-design bending moment with respect to $\mathrm{z}-\mathrm{z}$ axis & -2.300 & 0.572 & -0.090 \\
\hline $\mathrm{M}_{\mathrm{z}, \mathrm{c}, \mathrm{Rd}}(\mathrm{kNm})$ - design bending resistance with respect to $\mathrm{z}-\mathrm{z}$ axis & 102.827 & 16.511 & 4.892 \\
\hline Utilization $(\%)$ & 67 & 65 & 8 \\
\hline Maximum vertical displacement $(\mathrm{mm})$ —for node 79 & & 42.52 & \\
\hline Allowable vertical displacement $(\mathrm{mm})-\mathrm{D} / 300$ & & 83.33 & \\
\hline Maximum horizontal displacement ( $\mathrm{mm}$ )-for node 79 & & 3.93 & \\
\hline Allowable horizontal displacement (mm)—H/150 & & 6.67 & \\
\hline
\end{tabular}

Table 9. Cross sections taken for different groups of rods.

\begin{tabular}{ccc}
\hline Group Name & Nodes Nos & Cross Section \\
\hline Parallel & 2 to 81 & RO $219.1 \times 10$ \\
Meridian & 82 to 161 & RO $101.6 \times 8$ \\
Diagonal & 162 to 224 & RO $76.1 \times 4$ \\
\hline
\end{tabular}

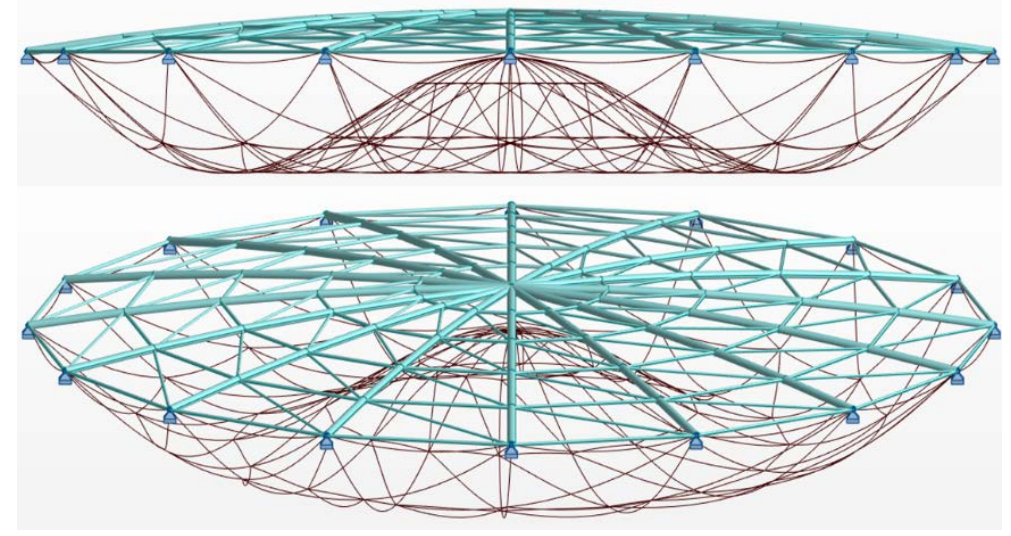

Figure 16. Ribbed dome deformation. 
a) $\mu=2.11199$

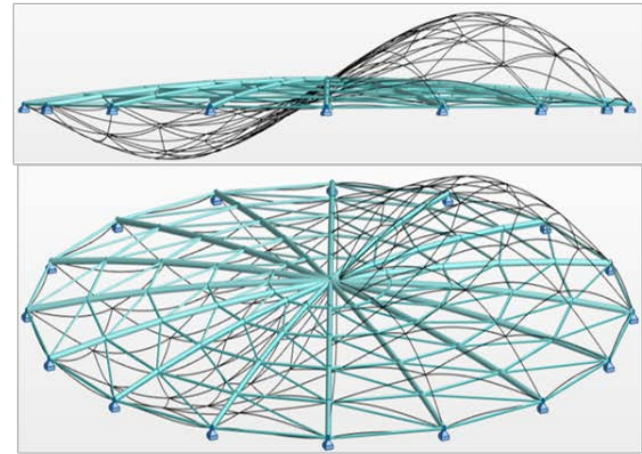

c) $\mu=3.22138$

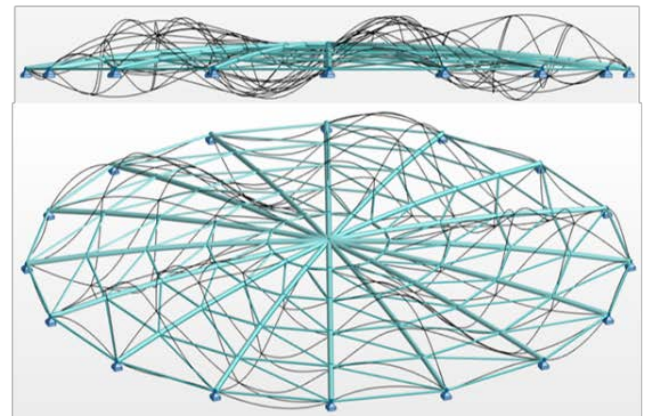

b) $\mu=2.11202$

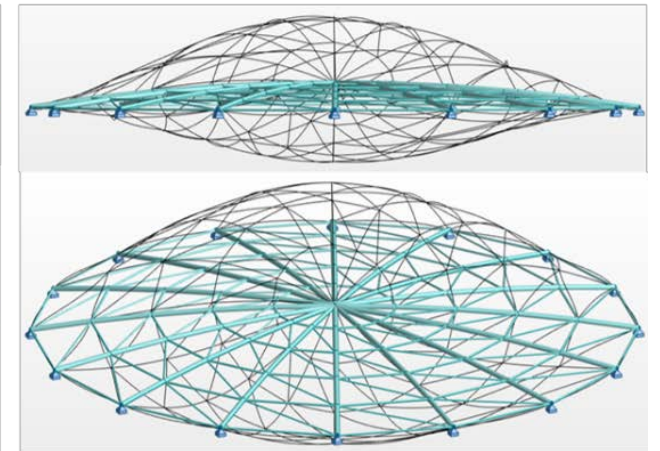

d) $\mu=3.22145$

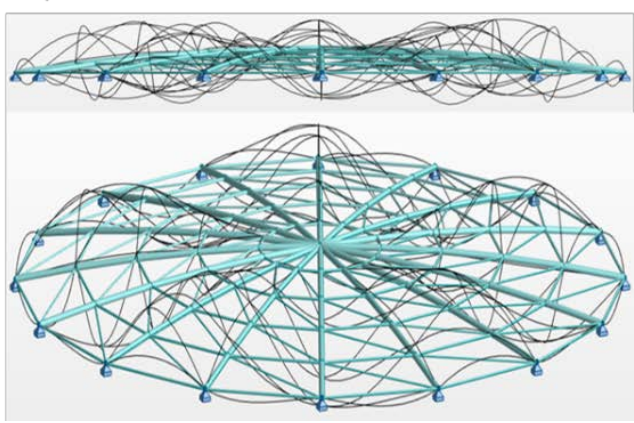

Figure 17. Buckling modes of the structure: (a) 1st, (b) 2nd, (c) 3rd, (d) 4th.

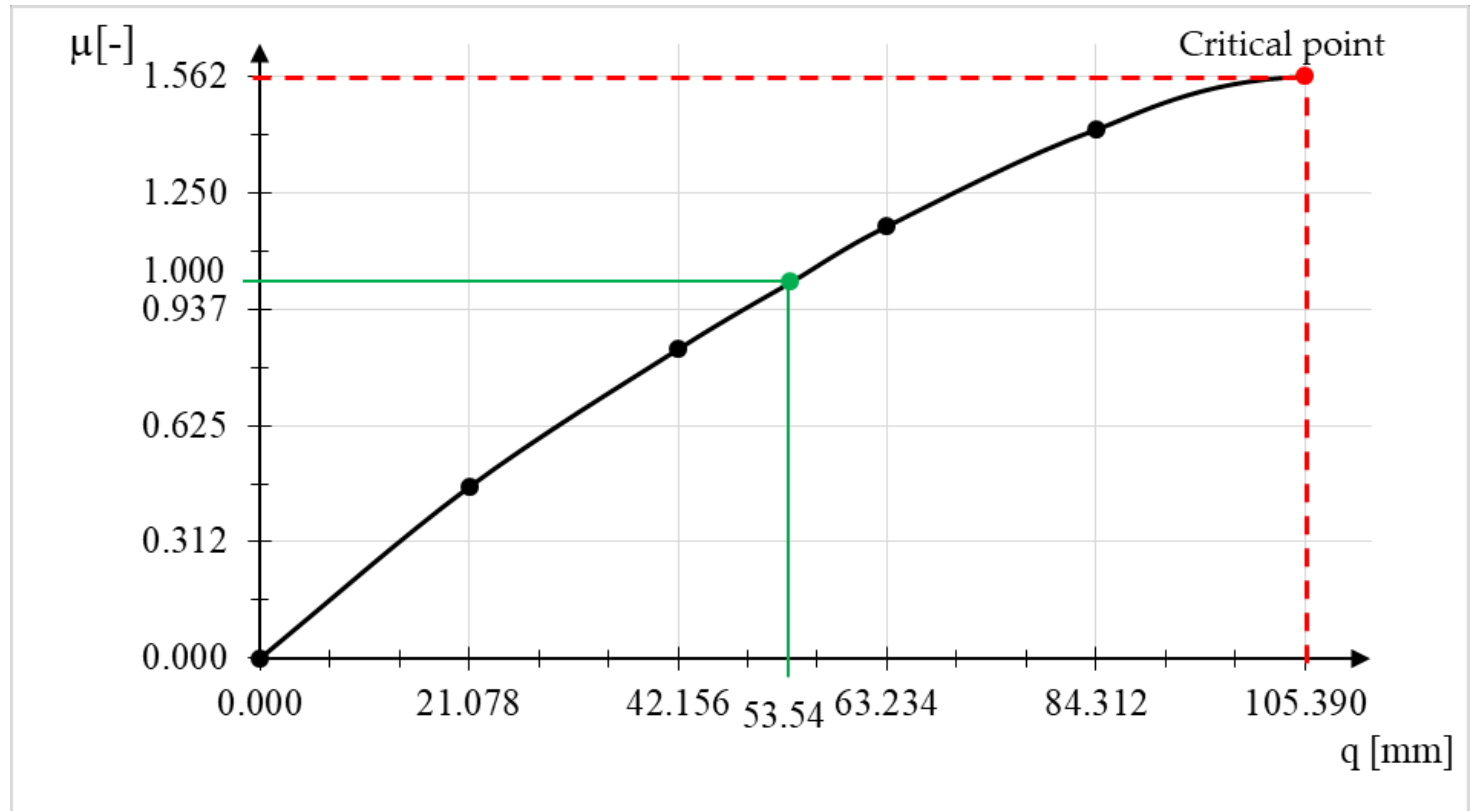

Figure 18. Equilibrium path of the considered bar dome for case 1.

Values of the internal forces and the maximum horizontal and vertical displacement of node 54, for the load multiplier $\mu$ equal to 1 , are presented in Table 10. 
Table 10. Values of the internal forces and the maximum horizontal and vertical displacement of node 54 for GNA.

\begin{tabular}{|c|c|c|c|}
\hline \multirow[b]{2}{*}{ Internal Forces/Displacement } & \multicolumn{3}{|c|}{ GNA } \\
\hline & $\begin{array}{l}\text { Meridian } \\
\text { Bar no } 20\end{array}$ & $\begin{array}{c}\text { Parallel } \\
\text { Bar no } 107\end{array}$ & $\begin{array}{c}\text { Diagonal } \\
\text { Bar no } 180\end{array}$ \\
\hline $\mathrm{N}_{\mathrm{Ed}}(\mathrm{kN})$-axial force & 596.243 & 208.020 & 1.61 \\
\hline $\mathrm{M}_{\mathrm{y}, \mathrm{Ed}, \mathrm{Max}}(\mathrm{kNm})$ - design bending moment with respect to $\mathrm{y}-\mathrm{y}$ axis & 39.097 & 0.825 & 0.431 \\
\hline $\mathrm{M}_{\mathrm{Z}, \mathrm{Ed}, \max }(\mathrm{kNm})$ - design bending moment with respect to $\mathrm{z}-\mathrm{Z}$ axis & -2.774 & -0.628 & -0.119 \\
\hline Utilization (\%) & 81 & 85 & 9 \\
\hline Maximum vertical displacement (mm)—for node 54 & & 53.54 & \\
\hline Allowable vertical displacement $(\mathrm{mm}) — \mathrm{D} / 300$ & & 83.33 & \\
\hline Maximum horizontal displacement (mm) — for node 54 & & 5.51 & \\
\hline Allowable horizontal displacement $(\mathrm{mm})-\mathrm{H} / 150$ & & 6.67 & \\
\hline
\end{tabular}

\subsubsection{Case 2. Load Combination $1.15 \times \mathrm{G}+1.5 \times \mathrm{S}+0.9 \times \mathrm{W}$}

In the second case, a situation was considered in which the load caused by uneven wind suction was additionally taken into account. Therefore, the considered structure was subjected to: permanent load (G) (self-weight of the steel structure and roofing) and snow load (S) for area 3 of snow load according to PN-EN-1991-1-3 [38] and uneven wind suction load (W) determined on the basis of PN-EN-1991-1-4 [39]. Cross sections of individual groups of members were adopted according to Table 9.

The values of cross-sectional forces, load capacity for the most-stressed elements of these groups, and the displacement limits of node 9 are summarized in Table 11. Figure 19 shows the deformation of the structure.

Table 11. Values of the internal forces and the maximum horizontal and vertical displacement of node 9 for LA.

\begin{tabular}{|c|c|c|c|}
\hline \multirow[b]{2}{*}{ Internal Forces/Displacement } & \multicolumn{3}{|c|}{ LA } \\
\hline & $\begin{array}{l}\text { Meridian } \\
\text { Bar no } 10\end{array}$ & $\begin{array}{c}\text { Parallel } \\
\text { Bar no } 106\end{array}$ & $\begin{array}{c}\text { Diagonal } \\
\text { Bar no } 165\end{array}$ \\
\hline $\mathrm{N}_{\mathrm{Ed}}(\mathrm{kN})$-axial force & 518.05 & 164.801 & 19.766 \\
\hline $\begin{array}{c}\mathrm{N}_{\mathrm{c}, \mathrm{Rd}}(\mathrm{kN}) \text { - design capacity of the section under uniform } \\
\text { compression }\end{array}$ & 1543.95 & 552.25 & 212.910 \\
\hline $\mathrm{N}_{\mathrm{b}, \mathrm{Rd}}(\mathrm{kN})$-design buckling resistance of the compressed element & 1486.389 & 275.405 & 43.369 \\
\hline $\mathrm{M}_{\mathrm{y}, \mathrm{Ed}, \mathrm{Max}}(\mathrm{kNm})$ - design bending moment with respect to $\mathrm{y}$-y axis & 29.862 & 0.693 & 0.122 \\
\hline $\mathrm{M}_{\mathrm{y}, \mathrm{c}, \mathrm{Rd}}(\mathrm{kNm})$ - design bending resistance with respect to $\mathrm{y}-\mathrm{y}$ axis & 102.827 & 16.511 & 4.892 \\
\hline $\mathrm{M}_{\mathrm{z}, \mathrm{Ed} \text {,max }}(\mathrm{kNm})$ - design bending moment with respect to $\mathrm{z}-\mathrm{Z}$ axis & -2.235 & -0.617 & -0.019 \\
\hline $\mathrm{M}_{\mathrm{z}, \mathrm{c}, \mathrm{Rd}}(\mathrm{kNm})$-design bending resistance with respect to $\mathrm{z}-\mathrm{z}$ axis & 102.827 & 16.511 & 4.892 \\
\hline Utilization $(\%)$ & 65 & 67 & 49 \\
\hline Maximum vertical displacement $(\mathrm{mm})$-for node 9 & & 48.42 & \\
\hline Allowable vertical displacement $(\mathrm{mm})-\mathrm{D} / 300$ & & 83.33 & \\
\hline Maximum horizontal displacement (mm)-for node 9 & & 4.52 & \\
\hline Allowable horizontal displacement (mm)-H/150 & & 6.67 & \\
\hline
\end{tabular}




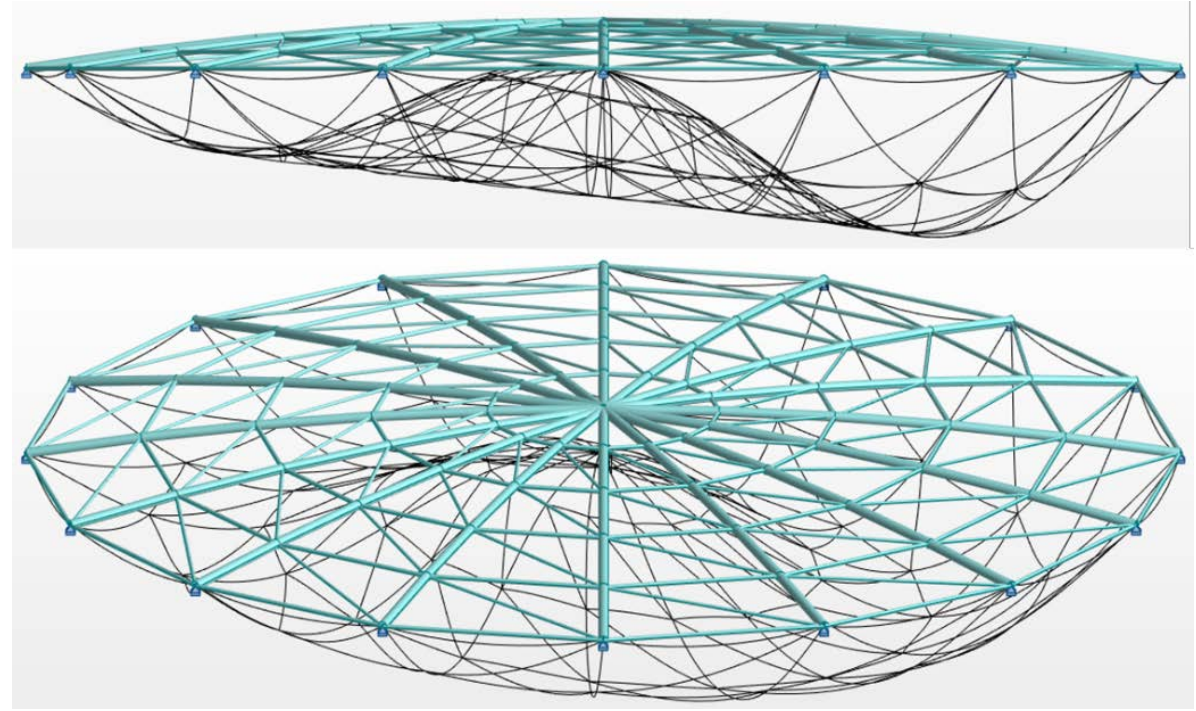

Figure 19. Ribbed dome deformation included wind load.

In the second step, the considered structure was subjected to linear buckling analysis. The lowermost critical load multiplier is equal to $\mu_{\mathrm{cr}}=2.35506$. Figure 20 shows the buckling modes for four successive eigenvalues.

a) $\mu=2.35506$

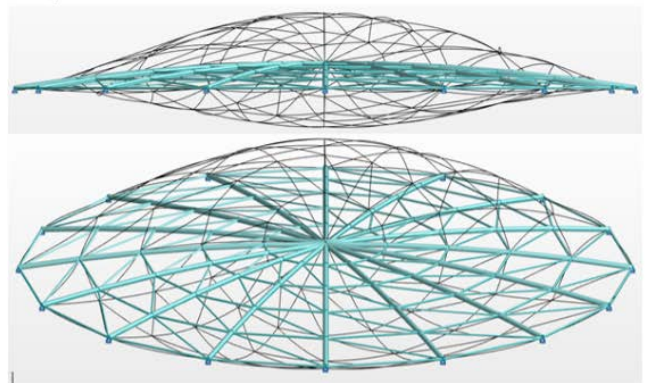

c) $\mu=3.42028$

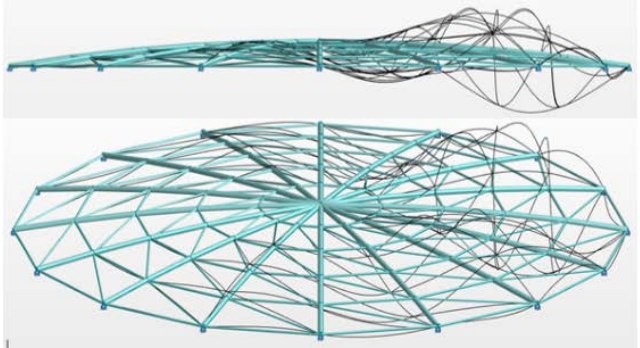

b) $\mu=2.369942$

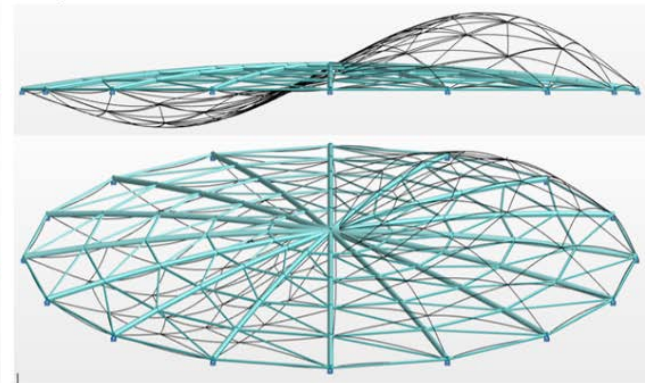

d) $\mu=3.42349$

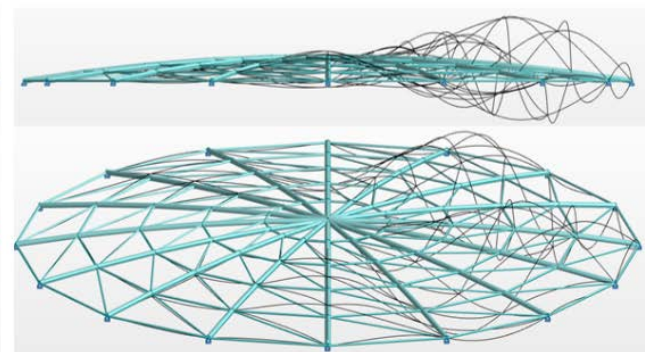

Figure 20. Buckling modes of the structure included wind suction: (a) 1st, (b) 2nd, (c) 3rd, (d) 4th.

In the last step, the geometrically nonlinear static analysis was carried out. The critical load multiplier is equal to $\mu_{\mathrm{cr}}=1.390$. Figure 21 shows the equilibrium path of the considered bar dome for case 2 . 


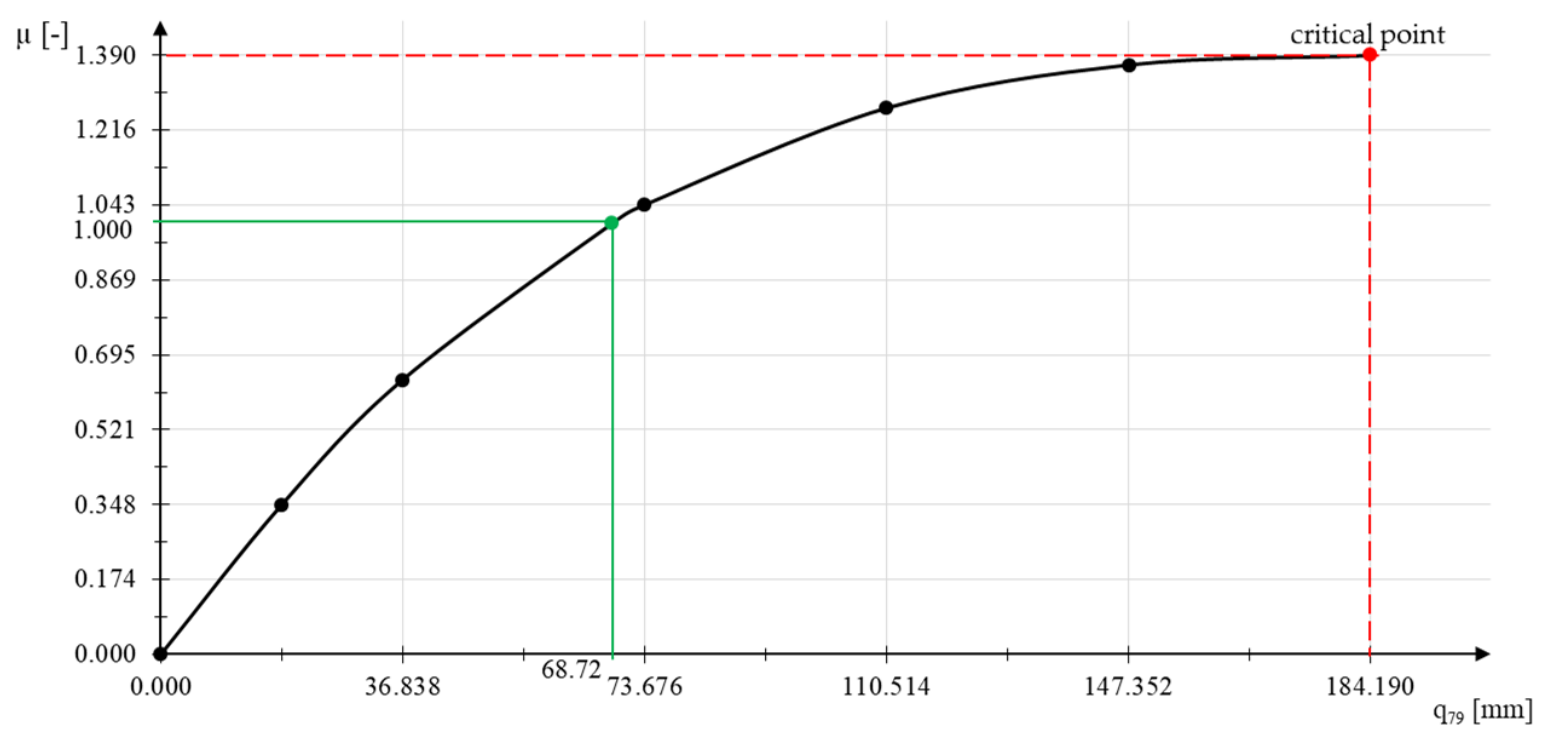

Figure 21. Equilibrium path of the considered bar dome for case 2.

Values of the internal forces and the maximum horizontal and vertical displacement of node 9 , for the load multiplier equal to 1 , are presented in Table 12.

Table 12. Values of the internal forces and the maximum horizontal and vertical displacement of node 9 for GNA.

\begin{tabular}{|c|c|c|c|}
\hline \multirow[b]{2}{*}{ Internal Forces/Displacement } & \multicolumn{3}{|c|}{ GNA } \\
\hline & $\begin{array}{l}\text { Meridian } \\
\text { Bar no } 10\end{array}$ & $\begin{array}{c}\text { Parallel } \\
\text { Bar no } 106\end{array}$ & $\begin{array}{c}\text { Diagonal } \\
\text { Bar no } 165\end{array}$ \\
\hline $\mathrm{N}_{\mathrm{Ed}}(\mathrm{kN})$-axial force & 555.081 & 214.545 & 36.408 \\
\hline $\mathrm{M}_{\mathrm{y}, \mathrm{Ed}, \mathrm{Max}}(\mathrm{kNm})$ - design bending moment with respect to $\mathrm{y}-\mathrm{y}$ axis & 43.965 & 1.210 & 0.173 \\
\hline $\mathrm{M}_{\mathrm{z}, \mathrm{Ed}, \max }(\mathrm{kNm})$ - design bending moment with respect to $\mathrm{z}-\mathrm{Z}$ axis & -2.704 & -0.720 & -0.008 \\
\hline Utilization (\%) & 83 & 92 & 90 \\
\hline Maximum vertical displacement ( $\mathrm{mm}$ )—for node 9 & & 68.72 & \\
\hline Allowable vertical displacement $(\mathrm{mm})-\mathrm{D} / 300$ & & 83.33 & \\
\hline Maximum horizontal displacement (mm)—for node 9 & & 6.52 & \\
\hline Allowable horizontal displacement $(\mathrm{mm})-\mathrm{H} / 150$ & & 6.67 & \\
\hline
\end{tabular}

\subsubsection{Discussion of Example 2}

The huge impact of uneven wind load on its load bearing capacity in the structure under consideration is clearly visible. During initial verification of cross-sections in linear analysis, an increase in utilization of the elements from the "diagonals" group to $49 \%$, compared to utilization of $8 \%$ in case 1 , was noticed. Changes in element utilization in the linear analysis for the other groups did not differ significantly and amounted: from $67 \%$ to $65 \%$ for meridians and from $65 \%$ to $67 \%$ for parallels, respectively. Larger differences were observed in geometric nonlinear analysis, and for meridians, the utilization increased from $81 \%$ to $83 \%$; in the case of parallels, from $85 \%$ to $92 \%$; and in the case of diagonals, from $9 \%$ to as much as $90 \%$. Differences in cross-sectional forces were also noted. In the linear analysis, the value of the axial force for meridians decreased from 563.694 to $518.05 \mathrm{kN}$; for parallels, increased from 162.79 to $164.801 \mathrm{kN}$; and for diagonals, increased from 1.977 to as much as $19.766 \mathrm{kN}$. Changes in the values of cross-sectional forces follow a similar trend in the case of GNA. For meridians, a decrease from 596.243 to $555.081 \mathrm{kN}$; for parallels, an increase from 208.020 to $214.545 \mathrm{kN}$; and for diagonals, an increase from 1.61 to as much as $36.408 \mathrm{kN}$ were observed.

The impact of uneven load is also noticeable on the value of the critical load multiplier determined in LBA. For case 1, it is $\mu_{\mathrm{cr}}=2.11199$, while in case 2 it increases to $\mu_{\mathrm{cr}}=2.35506$. Both values indicate 
that a second order analysis is necessary. The critical load multiplier values for geometrically nonlinear analysis are, respectively, for case $1, \mu_{\mathrm{cr}}=1.562$ and for case $2, \mu_{\mathrm{cr}}=1.390$.

\section{Conclusions}

Linear analysis with linear bifurcation analysis works well for the design of steel high-rise single-layer coverings. The situation changes radically when the structure is a low-rise single-layer bar dome. These structures are subjected to large displacement gradients, and the actual configuration has to be taken into account in analysis. During the analysis, a clear decrease in measures describing the stiffness of the structure was observed. This structures should be designed according to geometrically nonlinear analysis.

The nonlinear analysis of bar structures with the finite element method (FEM) involves solving large systems of nonlinear equations. The relation between displacements and loads in a $(\mathrm{N}+1)$-dimensional space is described by the load-displacement path. Stability analysis is closely related to singularities along this path. Controlling the incremental-iterative process to determine the equilibrium path and determine the location of critical points requires the establishment of a number of parameters. Their selection is not always intuitive and is time consuming. It often requires a lot of experience, but it is beneficial. The values of internal forces and displacements determined with two analyses mentioned above show very large differences. This concerns both the ultimate limit state and the serviceability limit state.

The paper focuses on comparing two load cases of low-rise bar domes, classic in accordance with Eurocodes requirements and taking into account uneven wind suction. Based on the analyses carried out, a significant impact of wind suction on the values of cross-sectional forces and displacements of structure nodes was observed. The use of stability analysis methods additionally enhanced the observed effect of the adverse effect of asymmetrical load on the structure. According to the authors, it is advisable to verify the load-bearing capacity of weak structures after taking into account the asymmetrical impact of wind on the structure.

Author Contributions: D.O., P.Z., and U.R. conceived and designed the experiments; D.O., P.Z., and U.R. performed the experiments; D.O., P.Z., and U.R. analyzed the data; D.O., P.Z., and U.R. contributed reagents/materials/analysis tools; D.O., P.Z., and U.R. wrote the paper. All authors have read and agreed to the published version of the manuscript.

Funding: This research received no external funding.

Conflicts of Interest: The authors declare no conflict of interest.

\section{References}

1. Kozłowski, A. Steel Structures. Examples of Calculations According to PN-EN-1993-1. Part I. Selected Elements and Connections; Oficyna Wydawnicza Politechniki Rzeszowskiej: Rzeszów, Poland, 2009. (In Polish)

2. Giżejowski, M.; Ziółko, J. General Construction, Steel Constructions of Buildings. Design According to Eurocodes with Examples of Calculations; Arkady: Warsaw, Poland, 2010; Volume 5. (In Polish)

3. PN-EN 1993-1-1. Eurocode 3: Design of Steel Structures. Part 1-1: General Rules and Rules for Buildings; PKN: Warsaw, Poland, 2005.

4. Szychowski, A. Stability of cantilever walls of steel thin-walled bars with open cross-section. Thin-Walled Struct. 2015, 94, 348-358. [CrossRef]

5. Szychowski, A. The stability of eccentrically compressed thin plates with a longitudinal free edge and with stress variation in the longitudinal direction. Thin-Walled Struct. 2008, 46, 494-505. [CrossRef]

6. Oda, H.; Usami, T. Stability design of steel plane frame by second-order elastic analysis. Eng. Struct. 1997, 19, 617-627. [CrossRef]

7. Fan, F.; Yan, J.; Cao, Z. Elasto-plastic stability of single-layer reticulated domes with initial curvature of members. Thin-Walled Struct. 2012, 60, 239-246. [CrossRef]

8. Ramalingam, R.; Jayachandran, S.A. Postbuckling behavior of flexibly connected single layer steel domes. J. Constr. Steel Res. 2015, 114, 136-145. [CrossRef] 
9. Plaut, R.H. Snap-through of shallow reticulated domes under unilateral displacement control. Int. J. Solids Struct. 2018, 148-149, 24-34. [CrossRef]

10. Xu, Y.; Han, Q.H.; Parke, G.A.R.; Liu, Y.M. Experimental Study and Numerical Simulation of the Progressive Collapse Resistance of Single-Layer Latticed Domes. J. Struct. Eng. 2017, 143. [CrossRef]

11. Yan, S.; Zhao, X.; Rasmussen, K.J.R.; Zhang, H. Identification of critical members for progressive collapse analysis of singlelayer latticed domes. Eng. Struct. 2019, 188, 111-120. [CrossRef]

12. Walport, F.; Gardner, L.; Real, E.; Arrayago, I.; Nethercot, D.A. Effects of material nonlinearity on the global analysis and stability of stainless steel frames. J. Constr. Steel Res. 2019, 152, 173-182. [CrossRef]

13. Koiter, W.T. On the Stability of Elastic Equilibrium; National Aeronautics and Space Administration: Washington, DC, USA, 1967.

14. Oden, J.T.; Fost, R.B. Convergence, accuracy and stability of finite element approximations of a class of non-linear hyperbolic equations. Numer. Methods Eng. 1973. [CrossRef]

15. Bathe, K.J. Finite Element Procedures in Engineering Analysis; Prentice Hall: New York, NY, USA, 1996.

16. Belytschko, T.; Liu, W.K.; Moran, B. Nonlinear Finite Elements for Continua and Structures; Wiley: Chichester, UK, 1997.

17. Kleiber, M. Some results in the numerical analysis of structural instabilities, Part 1 Statics. Eng. Trans. 1982, 30, 327-352.

18. Biegus, A. Basics of Design and Impact on Building Structures; Oficyna Wydawnicza Politechniki Wrocławskiej: Wrocław, Poland, 2014. (In Polish)

19. Biegus, A. Builder's Educational Notebooks. Issue 1. Basics of Structure Design. Actions on Structures. Steel Structure Design; Builder: Warsaw, Poland, 2011. (In Polish)

20. Bergan, P.G.; Soreide, T.H. Solution of large displacement and stability problem using the current stiffness parameter. In Proceedings of the Finite Elements in Nonlinear Mechanics, Geilo, Norway, September 1977; pp. 647-669.

21. Riks, E. An incremental approach to the solution of snapping and buckling problems. Int. J. Solids Struct. 1979, 15, 529-551. [CrossRef]

22. Riks, E. The application of Newton's method to the problem of elastic stability. J. Appl. Mech. 1972, 39, 1060-1065. [CrossRef]

23. Crisfield, M.A. A fast incremental/iterative solution procedure that handles snap-through. Comput. Struct. 1981, 13, 55-62. [CrossRef]

24. Ramm, E. Strategies for Tracing the Non-Linear Response Near Limit Points. Nonlinear Finite Element Analysis in Structural Mechanics; Springer: Berlin/Heidelberg, Germany, 1981; pp. 68-89.

25. Wempner, G.A. Discrete approximation related to nonlinear theories of solids. Int. J. Solids Struct. 1971, 7, 1581-1599. [CrossRef]

26. Ritto-Corrêa, M.; Camotim, D. On the arc-length and other quadratic control methods: Established, less known and new implementation procedures. Comput. Struct. 2008, 86, 1353-1368. [CrossRef]

27. Leon, S.E.; Paulino, G.H.; Pereira, A.; Menezes, I.F.M.; Lages, E.N. A Unified Library of Nonlinear Solution Schemes. Appl. Mech. Rev. 2011, 64, 040803. [CrossRef]

28. Rezaiee-Pajand, M.; Naserian, R.; Afsharimoghadam, H. Geometrical nonlinear analysis of structures using residual variables, Mechanics Based. Des. Struct. Mach. 2019, 47, 215-233. [CrossRef]

29. Waszczyszyn, Z.; Cichoń, C.; Radwańska, M. Stability of Structures by Finite Element Methods; Elsevier: Amsterdam, The Netherlands, 1994.

30. Pawlak, U.; Szczecina, M. Dynamic eigenvalue of concrete slab road surface. IOP Conf. Ser. Mater. Sci. Eng. 2017, 245, 22057. [CrossRef]

31. Kłosowska, J.; Obara, P.; Gilewski, W. Self-stress control of real civil engineering tensegrity structures. AIP Conf. Proc. 2018, 1922, 150004. [CrossRef]

32. Obara, P.; Kłosowska, J.; Gilewski, W. Truth and myth about 2D Tensegrity Trusses. Appl. Sci. 2019, 9, 179. [CrossRef]

33. Zabojszcza, P.; Radon, U. The Impact of Node Location Imperfections on the Reliability of Single-Layer Steel Domes. Appl. Sci. 2019, 9, 2742. [CrossRef]

34. Pecknold, D.A.; Ghaboussi, J.; Healey, T.J. Snap-through and bifurcation in a simple structure. J. Eng. Mech. ASCE 1985, 7, 909-922. [CrossRef] 
35. Ligarò, S.S.; Valvo, P.S. A self-adaptive strategy for uniformly accurate tracing of the equilibrium paths of elastic reticulated structures. Int. J. Num. Methods Eng. 1999, 46, 783-804. [CrossRef]

36. Ligarò, S.S.; Valvo, P.S. Large displacement analysis of elastic pyramidal trusses. Int. J. Solids Struct. 2006, 43, 4867-4887. [CrossRef]

37. Rezaiee-Pajand, M.; Rajabzadeh-Safaei, N. Exact post-buckling analysis of planar and space trusses. Eng. Struct. 2020, 223, 111146. [CrossRef]

38. PN-EN 1991-1-3: Eurocode 1: Actions on Structures-Part 1-3: General Actions-Snow Loads; PKN: Warsaw, Poland, 2005.

39. PN-EN 1991-1-4: Eurocode 1: Actions on Structures_Part 1-4: General Actions—Wind Actions; PKN: Warsaw, Poland, 2008.

40. PN-EN 1990:2004. Eurocode: Basis of Structural Design; PKN: Warsaw, Poland, 2008.

(C) 2020 by the authors. Licensee MDPI, Basel, Switzerland. This article is an open access article distributed under the terms and conditions of the Creative Commons Attribution (CC BY) license (http://creativecommons.org/licenses/by/4.0/). 